\title{
Chuvas intensas na bacia do rio Manuel Alves da Natividade, Tocantins, Brasil
}

\author{
Heavy rainfall in the Manuel Alves da Natividade river Watershed, Tocantins, Brazil \\ Lluvias intensas en la cuenca del río Manuel Alves da Natividade, Tocantins, Brasil
}

Tamara Thalia Prólo

ORCID: https://orcid.org/0000-0002-8921-3250 Instituto Federal de Educação Ciência e Tecnologia do Tocantins, Brasil E-mail: thaliprolo5@gmail.com

Virgilio Lourenço Silva Neto

ORCID: https://orcid.org/0000-0002-1004-0191 Instituto Federal de Educação Ciência e Tecnologia do Tocantins, Brasil E-mail: virgilio.neto@ifto.edu.br

Ezequiel Lopes do Carmo

ORCID: https://orcid.org/0000-0001-8794-2890 Instituto Federal de Educação Ciência e Tecnologia do Tocantins, Brasil E-mail: ezequiel.carmo@ifto.edu.br Otacilio Silveira Junior

ORCID: https://orcid.org/0000-0002-0784-5335 Instituto Federal de Educação Ciência e Tecnologia do Tocantins, Brasil E-mail: otacilio.junior@ifto.edu.br

Luziano Lopes da Silva

ORCID: https://orcid.org/0000-0003-0487-6301 Instituto Federal de Educação Ciência e Tecnologia do Tocantins, Brasil E-mail:luziano.silva@ifto.edu.br

\begin{abstract}
Resumo
A correta previsão e análise da distribuição espacial das precipitações pluviométricas intensas é importante para o planejamento dos recursos hídricos em bacias hidrográficas, além de dar suporte aos estudos climatológicos, meteorológicos e elaboração de projetos com finalidades distintas e/ou integradas. A utilização de técnicas de espacialização, disponíveis nos Sistemas de Informações Geográficas, facilita a verificação da forma como estas precipitações se distribuem no espaço, bem como a associação com diferentes fatores do ambiente. Estas técnicas permitem abranger grandes regiões com agilidade e precisão. Este estudo está voltado para o mapeamento de chuvas intensas na bacia hidrográfica do Rio Manuel Alves da Natividade. Foi feito o mapeamento de chuvas intensas com durações de 10, 20, 30, 40,50,60, 120, 180,360, 720 e 1440 minutos, associadas aos tempos de retorno de 5, 50 e 100 anos. Foram analisadas séries históricas de 25 postos pluviométricos, com período padronizado entre 1986 e 2016 . Foi constatado uma área com chuvas intensas de maior magnitude para curtas durações com 10, 20, 30 e 40 minutos, considerando os 3 tempos de retorno, na porção oeste da Bacia. Para durações de 50, 60, 120 e 180 minutos, com tempos de retorno de 5, 50 e 100 anos, a porção oeste da bacia apresentou as maiores intensidades, com destaque para o tempo de retorno de 100 anos. Nas durações 240, 360, 720 e 1440, apesar dos valores maiores serem encontrados na porção oeste, estes não representam grandes intensidades de precipitações, variando de 3 a $46 \mathrm{~mm} \mathrm{~h}^{-1}$.
\end{abstract}

Palavras-chave: Desagregação de chuva; Geoestatística; Hidrologia.

\begin{abstract}
The correct forecast and analysis of the spatial distribution of intense rainfall is important for the planning of water resources in hydrographic basins, in addition to supporting climatological and meteorological studies and the elaboration of projects with different and/or integrated purposes. The use of spatialization techniques, available in Geographic Information Systems, facilitates the verification of how these precipitations are distributed in space, as well as the association with different environmental factors. These techniques allow to cover large regions with agility and precision. This study is geared at mapping intense rainfall in the hydrographic basin of the Rio Manuel Alves da Natividade. The mapping of intense rains with durations of 10, 20, 30, 40, 50, 60, 120, 180, 360, 720 and 1440 minutes was made, associated with the return times of 5, 50 and 100 years. Historical series of 25 pluviometric stations were analyzed, with a standardized period between 1986 and 2016. An area with intense rain of greater magnitude was found for short durations with 10,20, 30 and 40 minutes, considering the 3 return times, in the western portion of the Basin. For durations of 50, 60, 120 and 180 minutes, with return times of 5, 50 and 100 years, the western portion of the basin showed the highest intensities, with an emphasis on the return time of 100 years. In durations 240, 360, 720 and 1440, although the highest values are found in the western portion, they do not represent great precipitation intensities, varying from 3 to $46 \mathrm{~mm} \mathrm{~h}^{-1}$.
\end{abstract}


Keywords: Rain breakdown; Geostatistics; Hydrology.

\section{Resumen}

La correcta predicción y análisis de la distribución espacial de lluvias intensas es importante para la planificación de los recursos hídricos en las cuencas hidrográficas, además de apoyar los estudios climatológicos y meteorológicos y la elaboración de proyectos con finalidades diferentes y/o integradas. El uso de técnicas de espacialización, disponibles en Sistemas de Información Geográfica, facilita la verificación de cómo se distribuyen estas precipitaciones en el espacio, así como la asociación con diferentes factores ambientales. Estas técnicas permiten cubrir grandes regiones con agilidad y precisión. Este estudio tiene como objetivo el mapeo de lluvias intensas en la cuenca hidrográfica del Rio Manuel Alves da Natividade. Se realizó el mapeo de lluvias intensas con duraciones de 10, 20, 30, 40, 50, 60, 120, 180, 360,720 y 1440 minutos, asociadas a los tiempos de retorno de 5, 50 y 100 años. Se analizaron series históricas de 25 estaciones pluviométricas, con un período estandarizado entre 1986 y 2016. Se encontró un área con lluvias intensas de mayor magnitud de corta duración con 10, 20, 30 y 40 minutos, considerando los 3 tiempos de retorno, en el occidente. porción de la Cuenca. Para duraciones de 50, 60, 120 y 180 minutos, con tiempos de retorno de 5, 50 y 100 años, la porción occidental de la cuenca mostró las intensidades más altas, con énfasis en el tiempo de retorno de 100 años. En las duraciones 240,360, 720 y 1440, aunque los valores más altos se encuentran en la porción occidental, no representan grandes intensidades de precipitación, variando de 3 a $46 \mathrm{~mm} \mathrm{~h}^{-1}$.

Palabras clave: Desagregación de lluvias; Geoestadística; Hidrología.

\section{Introduçãa}

O componente principal do ciclo hidrológico é a precipitação pluvial, a qual é diretamente responsável pela água que entra em uma bacia hidrográfica. Entretanto, há períodos com chuvas intensas em áreas com solos propensos à erosão (Mello \& Viola, 2013), provocando a desagregação das partículas do solo e inúmeras consequências negativas. A avaliação da precipitação pluvial é um dos elementos mais importantes nas áreas de manejo e conservação dos solos e da água, principalmente no que tange a desagregação de partículas do solo e escoamento superficial da água (Beskow, et al., 2009).

As chuvas intensas que ocorrem regionalmente podem ser analisadas através das probabilidades em modelos teóricos das séries históricas das precipitações máximas com determinada duração (Back, et al., 2012). Quando há disponibilidade, devese utilizar informações dos pluviogramas para obtenção e interpretação dos dados, de forma mais precisa. Portanto, uma das maneiras mais usuais e difundidas de estimativa de uma chuva intensa, consiste no uso de uma equação de chuvas intensas (Back, et al., 2012) que deve ser gerada para locais providos de séries históricas pluviográficas para que se possa tomar as melhores decisões quanto à exploração de determinada área.

No Brasil, a longa sequência dos dados pluviográficos de alta resolução temporal é rara. Por outro lado, as precipitações quantificadas diariamente são mais acessíveis, tanto ao tamanho da série quanto à densidade das redes (Hernandez, 2008), mas que compromete significativamente a interpretação e extrapolação dos dados para finalidades práticas de grande impacto, por exemplo, o preparo intensivo de diferentes tipos de solos em grandes áreas para o cultivo.

A utilização da Intensidade-Duração-Frequência (IDF) de chuvas intensas é aplicada, através dos modelos teóricos oriundos de séries pluviográficas de determinada localidade (Santos, et al., 2009) para previsão e tomada de importantes decisões, principalmente no que tange aos grandes revolvimentos de solos.

Quando não há dados em quantidade suficiente para se obter mapas de isolinhas ou mapas de contorno de precipitação pluvial para a área em estudo, é necessário recorrer a métodos que permitam estimar esses valores por meio das informações disponíveis. Normalmente, utiliza-se a técnica de interpolação, um procedimento de estimativa do valor de um atributo, em locais não amostrados, a partir de pontos amostrados na mesma área ou região (Carvalho, et al., 2002).

Frequentemente, os dados de precipitação pluvial são obtidos em postos de coleta pontuais, o que gera a necessidade de utilização de métodos de interpolação espacial para o seu mapeamento, entre os quais se destaca a krigagem (Carvalho \& Assad, 2005; Viola, et al., 2010).

No mapeamento da relação IDF, tendo em vista que o processo de mensuração envolve coleta de informação pontual em estações pluviométricas, frequentemente são empregados métodos de interpolação espacial, com destaque ao inverso do 
quadrado da distância e às técnicas geoestatísticas. A qualidade dos mapas obtidos por interpolação espacial é altamente dependente da procedência dos dados que servem de base para representatividade das séries históricas e para a distribuição espacial de informações das estações pluviométricas mais próximas (Reis, et al., 2005).

O interpolador geoestatístico pondera os vizinhos do ponto a ser estimado, obedecendo aos critérios de não tendenciosidade e variância mínima, gerando mapas não enviesados, uma vez que essa é a característica mais importante nos mapeamentos de variáveis contínuas (Isaaks \& Srivastava, 1989). Para isso, é imprescindível uma modelagem consistente do semivariograma experimental (Junqueira Junior, et al., 2008).

Os métodos de krigagem usam a dependência espacial expressa no semivariograma entre amostras vizinhas para estimar valores em qualquer posição dentro do campo, sem tendência e com variância mínima, o que os torna ótimos estimadores no estudo da distribuição espacial de precipitação pluvial (Machado, et al., 2010).

A bacia hidrográfica do rio Manuel Alves da Natividade ocupa 5,4\% da área total do Estado do Tocantins, a qual está inserida na região sudeste. O rio Manuel Alves da Natividade é um importante afluente pela margem direita do rio Tocantins, com relevantes demandas pelo uso dos recursos hídricos para agricultura, pecuária e abastecimento dos centros urbanos. Portanto, é essencial os estudos hidrológicos para subsidiar o planejamento e a tomada de decisão pelo Comitê de Bacia Hidrográfica local (Rodrigues, et al., 2015) e pelos profissionais relacionados às ciências agrárias.

Este estudo teve como objetivo o mapeamento de intensidades de chuvas para localidades inseridas na bacia hidrográfica do Rio Manuel Alves da Natividade, com durações de 10 a 1440 minutos, associadas aos tempos de retorno de 5, 50 e 100 anos.

\section{Metodologia}

Este trabalho é um estudo de caso, de natureza quantitativa, com base em grande quantidade de dados numéricos, analisados com base em técnicas geoestatísticas propiciando a espacialização da variável hidrológica por meio da utilização de equações matemáticas com o propósito da geração de mapas de chuvas intensas (Pereira et al., 2018).

Os dados pluviométricos foram obtidos junto ao Sistema de Informações Hidrológicas da Agência Nacional de Águas e Saneamento Básico (ANA, 2017), conforme mostra a Tabela 1. 
Tabela 1 - Estações pluviométricas utilizadas no presente estudo.

\begin{tabular}{|c|c|c|c|c|c|}
\hline \multirow{2}{*}{$\begin{array}{c}\text { Estação } \\
\text { Almas }\end{array}$} & \multirow{2}{*}{$\begin{array}{c}\text { Código } \\
01147000\end{array}$} & \multicolumn{2}{|c|}{ Localização } & \multirow{2}{*}{$\begin{array}{c}\text { Altitude } \\
(\mathrm{m}) \\
427\end{array}$} & \multirow{2}{*}{$\begin{array}{c}\text { Série histórica } \\
\text { (anos) }\end{array}$} \\
\hline & & $11,5789^{\circ} \mathrm{S}$ & $47,1739^{\circ} \mathrm{W}$ & & \\
\hline Aurora do Tocantins & 01246001 & $12,7639^{\circ} \mathrm{S}$ & $46,4086^{\circ} \mathrm{W}$ & 464 & 28 \\
\hline Campos Belos & 01346004 & $13,0767^{\circ} \mathrm{S}$ & $46,7769^{\circ} \mathrm{W}$ & 638 & 23 \\
\hline Colonha & 01248001 & $12,3875^{\circ} \mathrm{S}$ & $48,5442^{\circ} \mathrm{W}$ & 264 & 27 \\
\hline Conceição do Tocantins & 01247000 & $12,2325^{\circ} \mathrm{S}$ & $47,3244^{\circ} \mathrm{W}$ & 407 & 27 \\
\hline Dianópolis & 01146000 & $11,6253^{\circ} \mathrm{S}$ & $46,8106^{\circ} \mathrm{W}$ & 679 & 24 \\
\hline Fatima & 01048000 & $10,7636^{\circ} \mathrm{S}$ & $48,9022^{\circ} \mathrm{W}$ & 352 & 26 \\
\hline Faz. B. Jardim & 01145004 & $10,9925^{\circ} \mathrm{S}$ & $45,5267^{\circ} \mathrm{W}$ & 451 & 28 \\
\hline Faz. Joah & 01245014 & $12,1256^{\circ} \mathrm{S}$ & $45,8108^{\circ} \mathrm{W}$ & 725 & 28 \\
\hline Fazenda Lobeira & 01148000 & $11,5314^{\circ} \mathrm{S}$ & $48,2947^{\circ} \mathrm{W}$ & 243 & 30 \\
\hline Faz. Redenção & 01245004 & $12,1347^{\circ} \mathrm{S}$ & $45,1042^{\circ} \mathrm{W}$ & 490 & 28 \\
\hline Faz. Santa Rita & 01247005 & $12,5850^{\circ} \mathrm{S}$ & $47,4867^{\circ} \mathrm{W}$ & 340 & 26 \\
\hline Gurupi & 01149002 & $11,7372^{\circ} \mathrm{S}$ & $49,1361^{\circ} \mathrm{W}$ & 353 & 25 \\
\hline Natividade & 01147001 & $11,6969^{\circ} \mathrm{S}$ & $47,7283^{\circ} \mathrm{W}$ & 308 & 24 \\
\hline Nova Vida & 01145014 & $11,8525^{\circ} \mathrm{S}$ & $45,1222^{\circ} \mathrm{W}$ & 458 & 30 \\
\hline Pindorama do Tocantins & 01147002 & $11,1403^{\circ} \mathrm{S}$ & $47,5767^{\circ} \mathrm{W}$ & 444 & 33 \\
\hline Pium & 01049001 & $10,4411^{\circ} \mathrm{S}$ & $49,1792^{\circ} \mathrm{W}$ & 280 & 25 \\
\hline Ponte Alta & 01047004 & $10,7508^{\circ} \mathrm{S}$ & $47,5361^{\circ} \mathrm{W}$ & 300 & 29 \\
\hline Ponte Serafim & 01145013 & $11,8961^{\circ} \mathrm{S}$ & $45,6119^{\circ} \mathrm{W}$ & 713 & 29 \\
\hline Porto Alegre & 01147003 & $11,6100^{\circ} \mathrm{S}$ & $47,0450^{\circ} \mathrm{W}$ & 372 & 25 \\
\hline Porto Gilândia & 01047002 & $10,7553^{\circ} \mathrm{S}$ & $47,7647^{\circ} \mathrm{W}$ & 220 & 27 \\
\hline Rio da Palma & 01247002 & $12,4156^{\circ} \mathrm{S}$ & $47,1997^{\circ} \mathrm{W}$ & 322 & 24 \\
\hline F. do R. Preto & 01145001 & $11,0478^{\circ} \mathrm{S}$ & $45,2010^{\circ} \mathrm{W}$ & 489 & 31 \\
\hline Roda Velha & 01245015 & $12,7653^{\circ} \mathrm{S}$ & $45,9439^{\circ} \mathrm{W}$ & 761 & 26 \\
\hline Taquarussu & 01048005 & $10,3133^{\circ} \mathrm{S}$ & $48,1625^{\circ} \mathrm{W}$ & 406 & 26 \\
\hline
\end{tabular}

Fonte: ANA (2017).

A Tabela 1 descreve a localização geográfica e a altitude das estações pluviométricas utilizadas no presente estudo, a partir das quais o procedimento de mapeamento das chuvas intensas na bacia do Rio Manuel Alves da Natividade foi realizado. É importante destacar que a extensão da série histórica de cada estação varia entre 23 (Campos Belos) e 31 anos (Formosa do Rio Preto). Isto ocorreu em função de falhas observadas na constituição das séries, sendo então descartadas para maior confiabilidade dos dados utilizados.

Sendo assim, foram aplicadas séries históricas das 25 estações pluviométricas localizadas na Bacia do Rio Manuel Alves da Natividade e região de entorno, com período padronizado compreendido entre 1986 e 2016. 
Figura 1 - Modelo Digital de Elevação da Bacia do Rio Manuel Alves da Natividade com localização das estações pluviométricas utilizadas no estudo

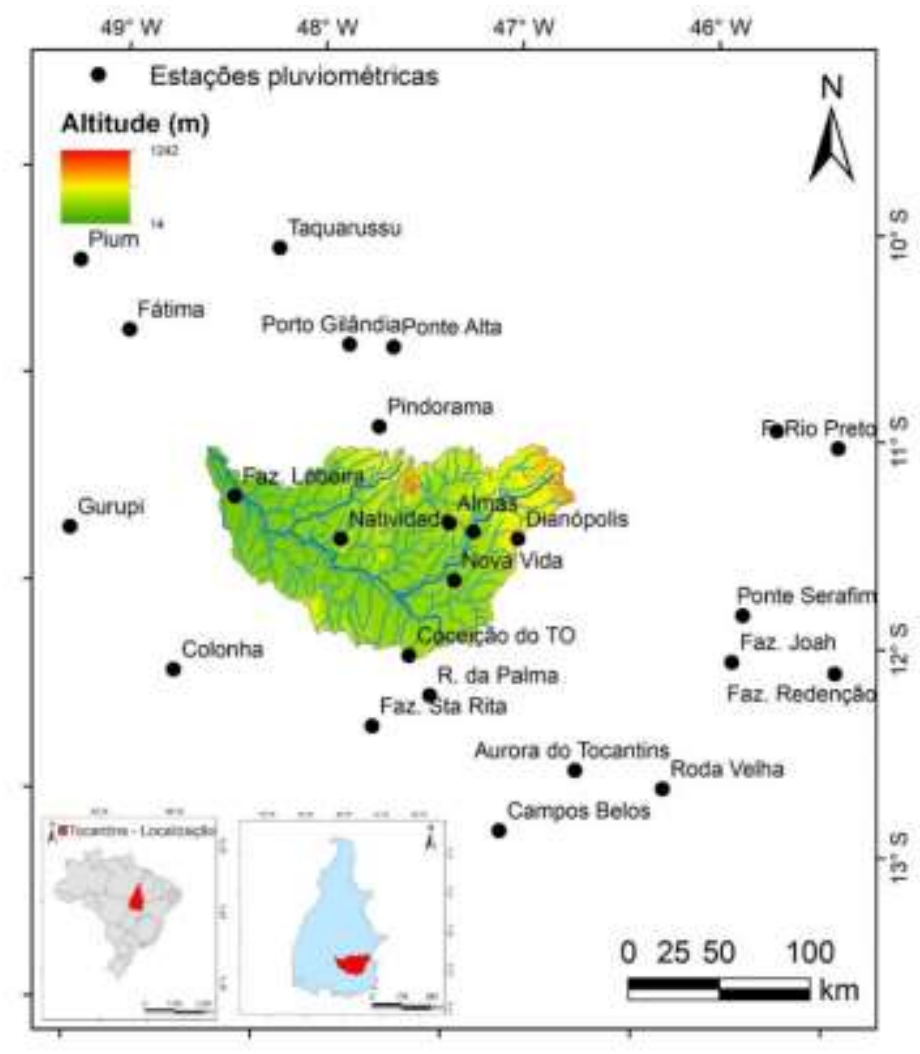

Fonte: Autores.

A Figura 1 apresenta a localização da área de estudo, bem como a espacialização das 25 estações pluviométricas utilizadas no estudo. Deve-se observar dentre elas, apenas 7 estão inseridas na área de drenagem do rio Manuel Alves da Natividade, sedo as demais 18 localizadas em seu entorno. A utilização de séries hidrológicas das proximidades da bacia, visa melhorar o mapeamento na região de contorno para adequada representação da estrutura de dependência espacial da variável (Alves, et al., 2016).

A distribuição de probabilidades de valores extremos do tipo I ou distribuição de Gumbel foi ajustada para modelar a frequência das chuvas intensas diárias na área da bacia do rio Manuel Alves da Natividade. Os parâmetros estatísticos (momentos de $1^{\mathrm{a}}$ e $2^{\mathrm{a}}$ ordens) foram aplicados para ajustar essa distribuição com base no método dos momentos, possibilitando estimar os valores associados a diferentes tempos de retorno. Essa distribuição foi ajustada às séries históricas de intensidades máximas de chuvas de 10 a 1440 minutos de duração para estimativa dos valores associados aos tempos de retorno de 5, 50 e 100 anos (Mello \& Viola, 2013).

A aderência da distribuição ajustada à série de máximas foi observada com o uso do o teste de Kolmogorov-Smirnov ao nível de significância 5\%.

A Função Densidade de Probabilidade (FDP) da distribuição Gumbel é dada por:

$$
f(x)=\alpha \cdot e^{\left[-\alpha \cdot(x-\mu)-e^{-\alpha \cdot(x-\mu)}\right]}
$$

Em que, x é a variável hidrológica em estudo, $\alpha$ é o parâmetro de escala da distribuição e $\mu$ é o parâmetro de localização da distribuição. 
$\alpha=\frac{1,2826}{\mathrm{~s}}$

$\mu=\overline{\mathrm{x}}-0,45 \cdot \mathrm{s}$

Em que $\bar{x}$ e $s$ correspondem à média e ao desvio padrão da série de máximas anuais, respectivamente.

A integração da FDP fornece a função cumulativa de probabilidade (FCP) que, na forma de excedência $[P(X \geq x)]$, é dada por:

$$
P(X \geq x)=1-e^{\left[-e^{(-\alpha .(x-\mu))}\right]}
$$

A estimativa da variável hidrológica associada a uma dada recorrência $\left(\mathrm{X}_{\mathrm{TR}}\right)$ é expressa por:

$$
\mathrm{X}_{\mathrm{TR}}=\frac{-\mathrm{LN}\left[-\mathrm{LN}\left(1-\frac{1}{\mathrm{TR}}\right)\right]}{\alpha}+\mu
$$

Em que, TR é o tempo de retorno, em anos.

Foram aplicadas as seguintes constantes de desagregação para o Estado do Tocantins: $\mathrm{h} 10_{\min } / \mathrm{h} 30_{\min }=0,46, \mathrm{~h} 20_{\min } / \mathrm{h} 30_{\min }$ $=0,76, \mathrm{~h} 30_{\min } / \mathrm{h} 60_{\min }=0,68, \mathrm{~h} 40_{\min } / \mathrm{h} 60_{\min }=0,83, \mathrm{~h} 50_{\min } / \mathrm{h} 60_{\min }=0,92, \mathrm{~h} 1 \mathrm{~h} / \mathrm{h} 24 \mathrm{~h}=0,61$, e h12 $/ \mathrm{h}_{24 \mathrm{~h}}=0,93$ (Silva Neto, et al., 2017) obtidas especificamente para o estado do Tocantins, onde se localiza a área de estudo. Estas foram obtidas através do método de relação entre durações e a relação $\mathrm{h} 24_{\mathrm{h}} / \mathrm{h}_{\text {dia }}$, a qual apresenta valor praticamente constante de 1,14 (CETESB, 1980).

Há de se destacar que o banco de dados utilizados por Silva Neto et al. (2017) não possuía a série de precipitações máximas diárias anuais para os 10 locais pesquisados pelos autores, o que determinou a impossibilidade de obter a relação $\mathrm{h} 24_{\mathrm{h}} / \mathrm{h}_{\text {dia. }}$. No entanto, isso não se caracterizou como uma limitação para a aplicação das constantes desenvolvidas pelos autores, visto que, segundo a CETESB (1980), a relação h24h/h $\mathrm{h}_{\text {dia }}$ apresenta um valor quase constante de 1,14 (Silva Neto, et al., 2017).

Com os valores obtidos de chuvas máximas para diferentes durações e tempos de retorno, estimaram-se os parâmetros da equação que expressa a relação IDF (Equação 6), para cada estação observada.

$$
\mathrm{i}=\frac{\mathrm{C} \cdot \mathrm{TR}^{\mathrm{m}}}{\left(\mathrm{t}_{\mathrm{o}}+\mathrm{t}_{\mathrm{d}}\right)^{\mathrm{n}}}
$$

Em que, i é a intensidade média máxima de precipitação em $\mathrm{mm} \cdot \mathrm{h}^{-1}$, TR é o período de retorno em anos, td equivale ao tempo de duração da chuva (minutos) e $\mathrm{C}, \mathrm{m}$, to e n são parâmetros relativos à localidade.

Tomando como procedimento preliminar, "é essencial o ajuste do modelo de semivariograma teórico, para obtenção dos valores para os parâmetros que estruturam esses modelos (efeito pepita, contribuição e alcance)" (Silva Neto, et al., 2021, p. 4). Para este trabalho desenvolvido na Baca do rio Manuel Alves da Natividade, foram analisados os modelos de semivariograma esférico, exponencial e gaussiano, com aplicação do método de ajuste dos Mínimos Quadrados Ponderados (MQP).

Nas Equações 7, 8 E 9 estão apresentados os modelos de semivariograma esférico, exponencial e gaussiano, respectivamente.

$$
\begin{aligned}
& \gamma(\mathrm{h})=\mathrm{C}_{0}+\mathrm{C}_{1} \cdot\left[\frac{3}{2} \cdot\left(\frac{\mathrm{h}}{\mathrm{a}}\right)-\frac{1}{2} \cdot\left(\frac{\mathrm{h}}{\mathrm{a}}\right)^{3}\right], \text { se } 0<h<a ; \gamma(h)=C 0+C 1 ; h \geq a \\
& \gamma(\mathrm{h})=\mathrm{C}_{0}+\mathrm{C}_{1} \cdot\left[1-\exp \left(\frac{-3 \cdot \mathrm{h}}{\mathrm{a}}\right)\right], \text { se } 0<h<a ; \gamma(h)=C 0+C 1 ; h>a \\
& \gamma(\mathrm{h})=\mathrm{C}_{0}+\mathrm{C}_{1} \cdot\left\{1-\exp \left[-3 \cdot\left(\frac{\mathrm{h}}{\mathrm{a}}\right)^{2}\right]\right\}, \text { se } 0<h<a ; \gamma(h)=C 0+C 1 ; h>a
\end{aligned}
$$


Sendo, $\gamma(h)$ a semivariância, $\mathrm{C}_{1}$ a contribuição do semivariograma (diferença entre o patamar e o efeito pepita), $a \mathrm{o}$ alcance, $\mathrm{C}_{0} \mathrm{o}$ efeito pepita e $h$ a distância entre os pares de pontos.

Com o intuito de analisar a estrutura de dependência espacial dos modelos de semivariograma ajustados, foi calculado o grau de dependência espacial (GD), sendo obtido conforme Cambardella et al. (1994) por:

$$
\mathrm{GD}=\left(\frac{\mathrm{C}_{1}}{\mathrm{C}_{0}+\mathrm{C}_{1}}\right) \cdot 100
$$

Considerando o GD, pode-se adotar a seguinte classificação: GD < 25\% (fraco), entre 25 e $75 \%$ (moderado) e > $75 \%$ (forte) (Cambardella, et al., 1994).

Visando verificar o modelo de semivariograma que se sobressaiu, foi realizada a validação cruzada. Foi quantificado o Erro Médio Percentual Absoluto (EMPA), possibilitando a identificação do modelo que produziu o menor erro de estimativa, e que foi definido para o mapeamento de cada evento em análise. O EMPA, em \%, foi calculado utilizando a seguinte expressão:

$$
\mathrm{EMPA}=\frac{1}{\mathrm{n}} \cdot \sum_{\mathrm{i}=1}^{\mathrm{n}}\left|\frac{\mathrm{Obs}_{\mathrm{i}}-\mathrm{Est}_{\mathrm{i}}}{\mathrm{Obs}_{\mathrm{i}}}\right| \cdot 100
$$

Em que, $n$ é o número de postos pluviométricos, $O b s_{i}$ é a precipitação observada para o posto i e $E s t_{i}$ é a precipitação estimada por krigagem para a posição do posto $i$.

Através da Ferramenta Geoestatística ArcGis $10.02 \circledast$ foi aplicada a krigagem ordinária, foram gerados mapas da precipitação máxima diária anual e de chuvas intensas com durações de 10, 20, 30, 40, 50, 60, 120, 180, 240, 360, 720 e 1440 minutos, associadas aos tempos de retorno de 10, 50 e 100 anos. Foi adotado o sistema de Coordenadas SIRGAS 2000 para a elaboração dos mapas.

\section{Resultados e Discussão}

Na Tabela 2 encontram-se os valores obtidos no teste de Kolmogorov-Smirnov, onde todas as estações foram aprovadas em um teste a 5\% de significância. 
Tabela 2 - Erro máximo de ajuste da distribuição de Gumbel visando a aplicação do Teste de Kolmogorov-Smirnov para as séries de precipitação máxima com durações entre 10 e 1440 minutos para as 25 estações utilizadas neste estudo.

\begin{tabular}{|c|c|c|}
\hline \multirow{2}{*}{ Estação } & \multicolumn{2}{|c|}{ Kolmogorov-smirnov } \\
\hline & Valor obtido & Valor tabelado \\
\hline Almas & 0,112 & 0,250 \\
\hline Aurora do Tocantins & 0,075 & 0,246 \\
\hline Campos Belos & 0,176 & 0,269 \\
\hline Colonha & 0,107 & 0,250 \\
\hline Conceição do Tocantins & 0,115 & 0,250 \\
\hline Dianópolis & 0,132 & 0,264 \\
\hline Fatima & 0,159 & 0,254 \\
\hline Faz. B. Jardim & 0,143 & 0,246 \\
\hline Faz. Joah & 0,082 & 0,246 \\
\hline Fazenda Lobeira & 0,088 & 0,238 \\
\hline Faz. Redenção & 0,065 & 0,246 \\
\hline Faz. Santa Rita & 0,119 & 0,254 \\
\hline Gurupi & 0,123 & 0,259 \\
\hline Natividade & 0,093 & 0,264 \\
\hline Nova Vida & 0,115 & 0,238 \\
\hline Pindorama do Tocantins & 0,060 & 0,227 \\
\hline Pium & 0,134 & 0,259 \\
\hline Ponte Alta & 0,146 & 0,242 \\
\hline Ponte Serafim & 0,115 & 0,238 \\
\hline Porto Alegre & 0,121 & 0,259 \\
\hline Porto Gilândia & 0,078 & 0,250 \\
\hline Rio da Palma & 0,112 & 0,264 \\
\hline F. do R. Preto & 0,097 & 0,234 \\
\hline Roda Velha & 0,153 & 0,254 \\
\hline Taquarussu & 0,097 & 0,254 \\
\hline
\end{tabular}

Fonte: Autores.

Os resultados apresentados na Tabela 2 demonstram, por meio da aplicação do teste Kolmogorov-Smirnov, a adequabilidade da distribuição Gumbel. Observou-se que o ajuste da distribuição de probabilidades Gumbel para as 25 séries de precipitação foi adequado, corroborando diversos estudos sobre as chuvas intensas, tais como Mello e Viola (2013), Silva Neto et al. (2020), que ao realizarem procedimento análogo, também verificaram que o modelo teórico de distribuição de probabilidade Gumbel propiciou ajuste adequado.

Para a estação Fazenda Bom Jardim no ano de 1983 a precipitação máxima diária anual foi de apenas 25 mm, valor muito abaixo do esperado. Fazendo uma comparação com a estação mais próxima, pode-se inferir que houve uma variação nos dados, pois no mesmo ano, para a estação de Formosa, a precipitação máxima diária anual foi de $71 \mathrm{~mm}$. Com relação ao teste de Kolmogorov-Smirnov ao nível 5\% de significância, é possível afirmar que o ajuste de distribuição de probabilidades Gumbel para as 25 séries de precipitação máxima diária anual foi adequado, o que justifica o emprego desta distribuição no estudo das 
chuvas intensas, em conformidade com os resultados encontrados por Cardoso et al. (1998), Mello et al. (2001), Silva et al. (2002), Damé et al. (2006), Back et al. (2012), Damé et al. (2010) e Caldeira et al. (2016).

Na Tabela 3 encontram-se os parâmetros dos modelos de semivariograma (efeito pepita, contribuição e alcance), o viés (ou tendência) estatístico, erro médio percentual absoluto e o grau de dependência espacial obtido pelos modelos de semivariograma esférico, exponencial e gaussiano, para a precipitação máxima diária anual na bacia do rio Manuel Alves da Natividade.

Tabela 3 - Parâmetros dos modelos de semivariograma esférico, exponencial e gaussiano [efeito pepita $\left(\mathrm{C}_{0}\right)$, alcance $(A)$, contribuição (C1), erro médio percentual absoluto (EMPA), viés estatístico (BIAS) e grau de dependência (GD)].

\begin{tabular}{lcccccc}
\hline Modelo & $\mathrm{C}_{0}$ & $\mathrm{~A}(\mathrm{~m})$ & $\mathrm{C} 1$ & EMPA (\%) & BIAS (\%) & GD (\%) \\
\hline Esférico & 0,00 & 124525,16 & 38,24 & 4,02 & $-0,13$ & 100,00 \\
Exponencial* & 0,00 & 157893,16 & 40,35 & 3,96 & $-0,08$ & 100,00 \\
Gaussiano & 3,06 & 107141,20 & 36,51 & 4,06 & $-0,12$ & 92,27 \\
\hline
\end{tabular}

* Modelo que apresentou melhor ajuste. Fonte: Autores.

Com base na Tabela 3, observa-se que os valores do EMPA demonstraram menores erros produzidos pelo modelo exponencial (3,96\%), seguido pelos modelos esférico e gaussiano, com 4,02\% e 4,06\%, respectivamente. O menor viés estatístico foi apresentado pelo modelo exponencial $(-0,08 \%)$, seguido pelo modelo gaussiano $(-0,12 \%)$ e exponencial $(-0,13 \%)$.

$\mathrm{Na}$ Figura 2 apresentam-se os modelos teóricos exponencial, esférico e gaussiano, ajustados ao semivariograma experimental.

Figura 2 - Semivariogramas teóricos ajustados para o mapeamento da precipitação máxima diária anual no Tocantins. (a) Esférico, (b) Exponencial e (c) Gaussiano.
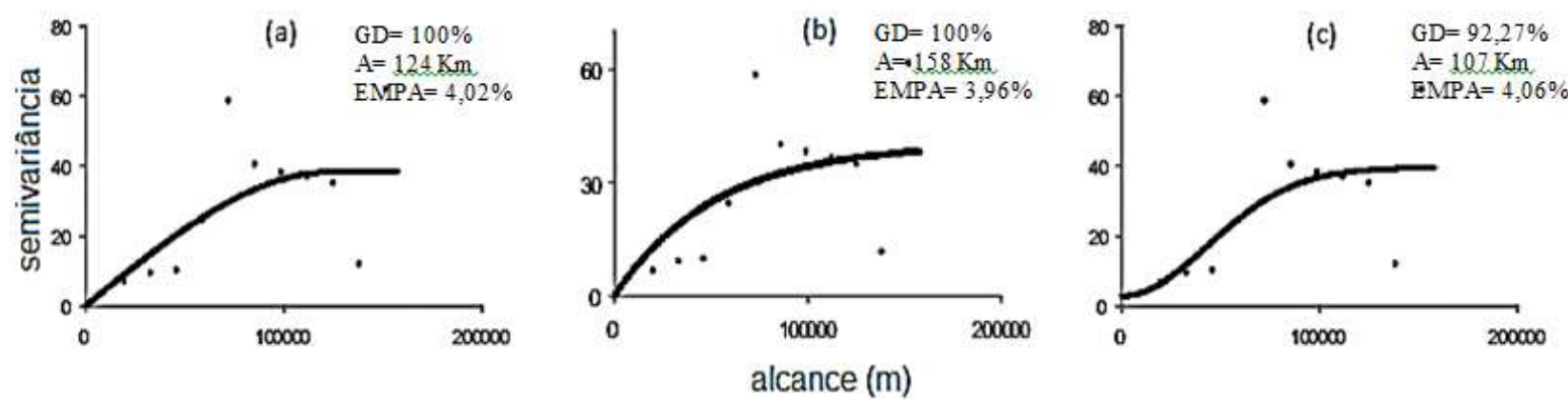

Fonte: Autores.

A Figura 2 dá atenção espacial, além da dependência espacial e ao erro médio percentual absoluto, a um elemento geoestatístico: o alcance. $\mathrm{Na}$ análise geoestatística é de fundamental importância para interpretação dos dados o conhecimento sobre alcance do semivariograma, sendo este, a representação da distância limite da dependência espacial. Neste estudo, apresentou um valor de $158 \mathrm{Km}$, que permite, segundo Mello et al. (2005), realizar mapeamentos geoestatísticos com excelentes resultados. Alves et al. (2016) em estudos da distribuição da precipitação mensal, anual e máxima diária anual na bacia hidrográfica do rio Formoso, verificou melhores resultados para o modelo gaussiano em 50\% das análises, enquanto que para os modelos exponencial e esférico foram $21,4 \%$ e 28,6\%, respectivamente. Em uma análise mais ampla, considerando todo o estado, Silva Neto et al. (2020) obtiveram um melhor desempenho do modelo esférico (EMPA 5,59\%) em estudos de mapeamento de chuvas intensas para o estado do Tocantins. 
Os resultados demonstram GD equivalente a 100\% para os modelos esférico e exponencial, que se sobressaíram em relação ao modelo gaussiano, demonstrando forte grau de dependência espacial (> 75\%) para os valores de precipitação máxima diária anual, para os três modelos testados.

Observa-se na Figura 3 que as porções oeste e o centro-oeste da bacia podem ser consideradas críticas com relação à ocorrência da chuva intensa diária, com valores de $82 \mathrm{~mm}$ até $100 \mathrm{~mm}$. Portanto, nessas regiões os cuidados devem ser maiores em áreas mais declivosas, principalmente quanto ao preparo do solo para o cultivo. Segundo Tucci e Clarke (1997) o uso do solo para plantio anual, após o desmatamento, depende muito do preparo do solo e dos cuidados com o escoamento gerado. O plantio sem nenhum cuidado com a conservação do solo, tende a aumentar consideravelmente a erosão, com grande aumento no escoamento com relação às condições previas de floresta. Os solos predominantes na área da bacia são os Argissolos e Plintossolos. Os Argissolos tendem a ser mais suscetíveis aos processos erosivos, devido à relação textural presente nestes solos, que implica em diferenças de infiltração dos horizontes superficiais e subsuperficiais. O Plintossolo também apresenta relativa suscetibilidade a processos erosivos, devido ao endurecimento da plintita, o que diminui a infiltração de água. Na porção leste da bacia, verificou-se chuvas diárias com menores alturas precipitadas, que variaram de 72 a $82 \mathrm{~mm}$.

Observa-se na Figura 3 que a região do município de Santa Rosa do Tocantins está localizada na área com maiores intensidades de chuva. Este município é considerado dentro da bacia hidrográfica do rio Manuel Alves como o maior produtor agrícola, com aproximadamente 41 mil ha e com as culturas mais exploradas como a soja, o milho e o feijão (IBGE, 2019). Como estas culturas são consideradas de lavouras temporárias e as quais apresentam a parte aérea muito tenra na maior parte do ciclo produtivo, conforme a intensidade das chuvas, pode comprometer a produtividade da respectiva espécie e consequentemente provocar consideráveis prejuízos aos produtores e para o município. Já nos locais de menor intensidade para os períodos de retorno de 5, 50 e 100 anos, está localizado o município de Conceição do Tocantins, considerado um dos menos populosos e de menor expressão agrícola. 
Figura 3 - Precipitação máxima diária anual $(\mathrm{mm})$ para a área de estudo com delimitação dos municípios localizados na bacia e Rede de drenagem da Bacia do Rio Manuel Alves da Natividade (B).

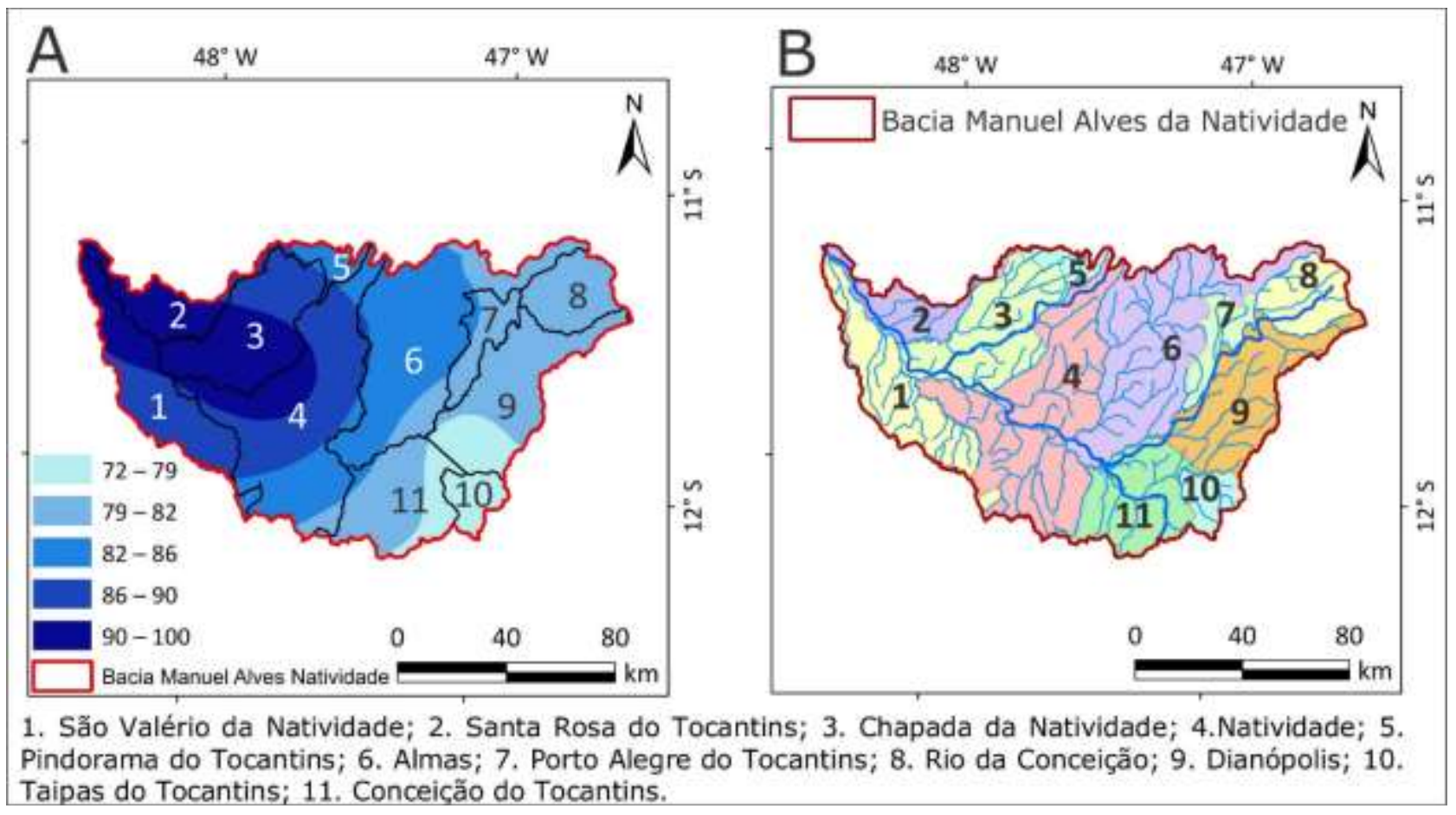

Fonte: Autores.

É possível observar na Figura 3, considerando os limites da área de estudo, que os maiores valores de precipitação máxima diária anual estão concentrados ao noroeste da bacia, onde se localizam as porções dos municípios de São Valério da Natividade, Santa Rosa do Tocantins e Chapada da Natividade, além de uma concentração também ao oeste do município de Natividade.

Os resultados da análise semivariográfica das chuvas intensas obtidas por desagregação da precipitação máxima diária anual, associada aos tempos de retorno de 5, 50 e 100 anos estão apresentados nas Figuras 4 e 5 . Observa-se que para as 36 situações analisadas, os modelos gaussiano e esférico se sobressaíram com os menores valores de EMPA, embora o modelo exponencial tenha se sobressaído para a precipitação máxima diária anual. O número de classes utilizadas nas legendas do processo de geração dos mapas apresentou variações, a fim de melhorar a visualização das informações, devido a pequena amplitude de algumas classes. Houve também a necessidade de reduzir a quantidade de classes em alguns mapas. 
Figura 4 - Semivariogramas ajustados para a chuva intensa de 10(a), 20(b), 30(c), 40(d), 50(e) e 60(f) minutos associadas aos tempos de retorno de 5, 50 e 100 anos, na Bacia do Rio Manuel Alves da Natividade, com destaque para o grau de dependência espacial (GD), alcance (A) e erro médio percentual absoluto obtido por validação cruzada (EMPA).
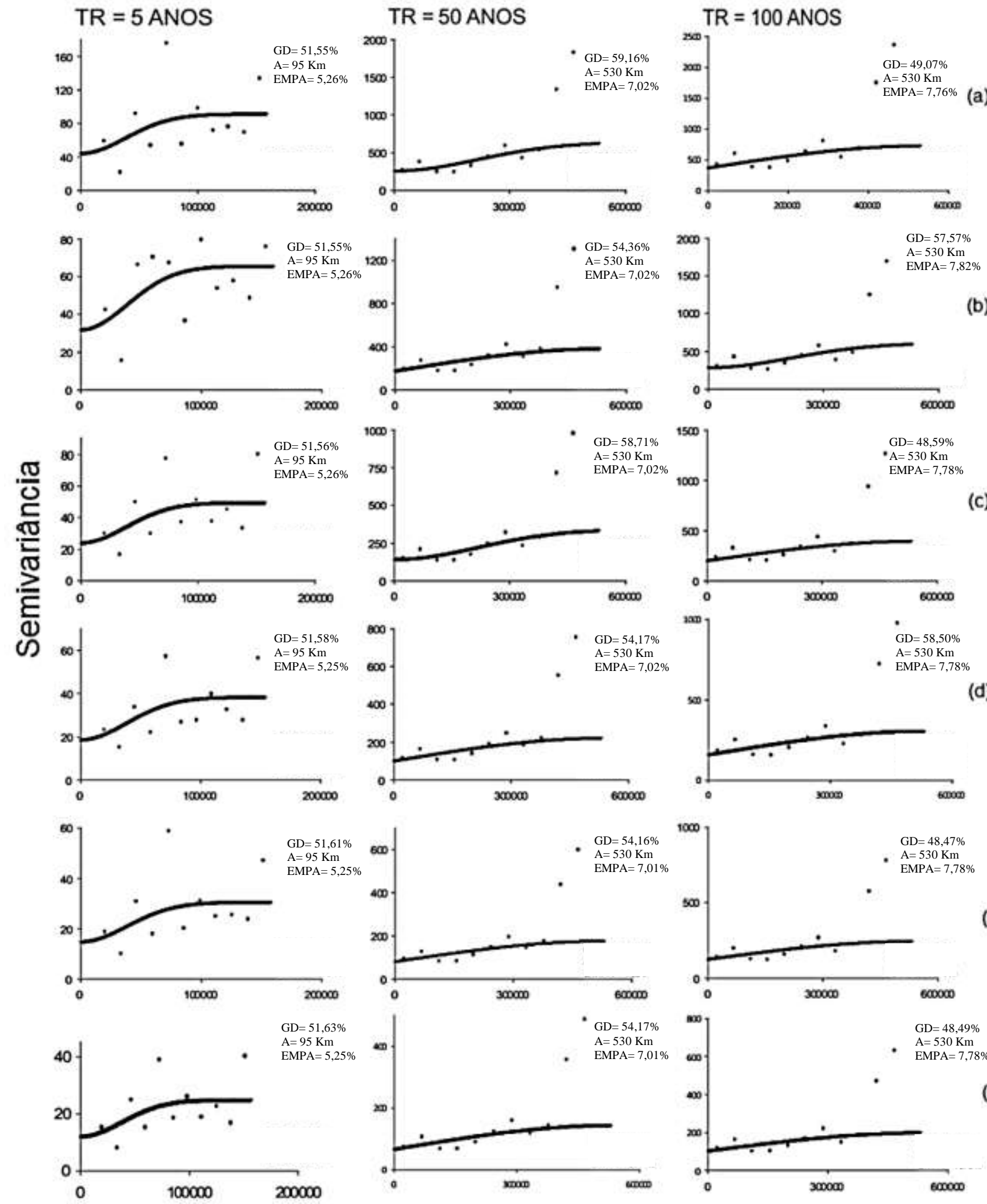

(b)
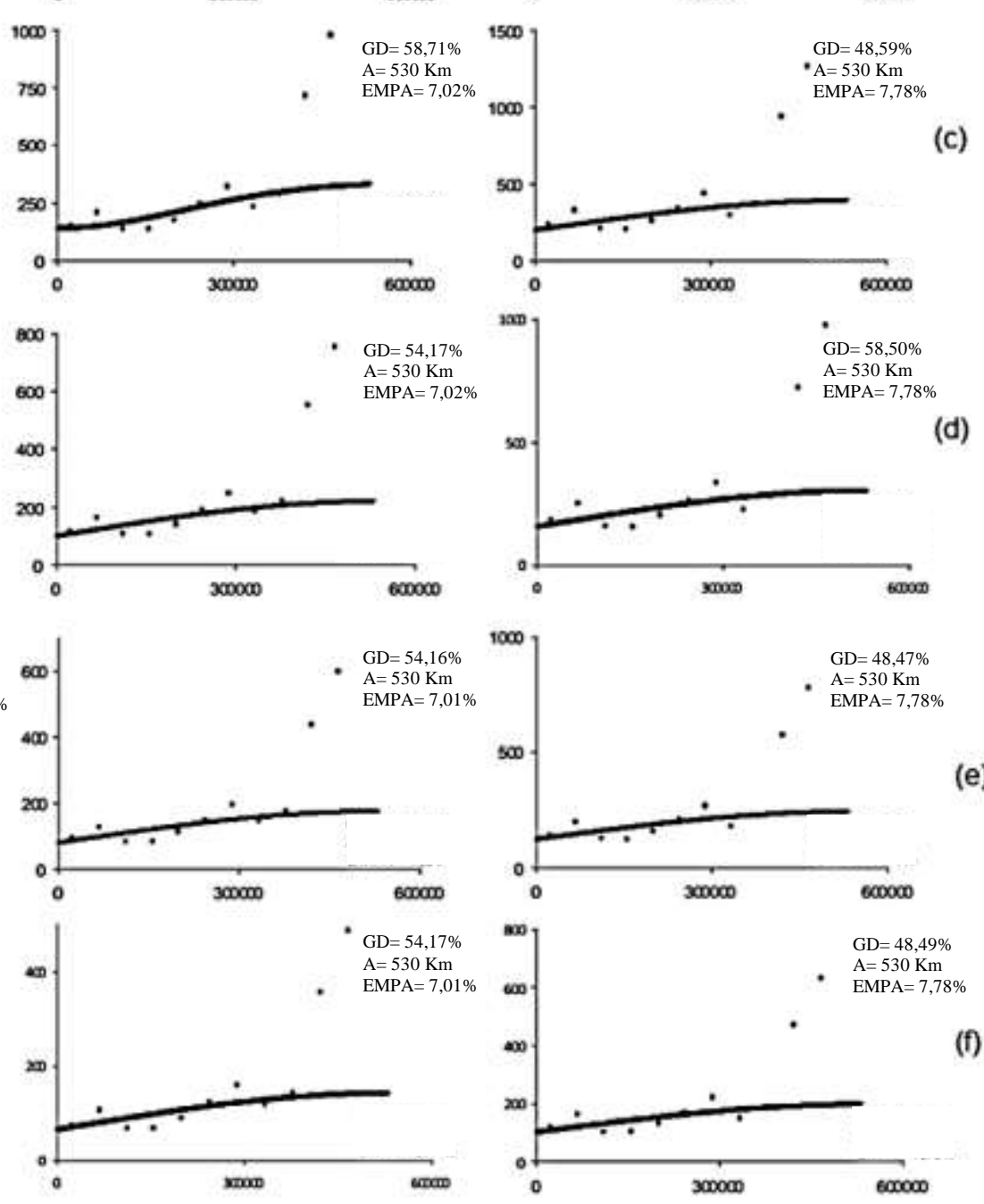

Distância (m)

Fonte: Autores. 
Figura 5 - Semivariogramas ajustados para a chuva intensa de 120(a), 180(b), 240(c), 360(d), 720(e) e 1440(f) minutos associadas aos tempos de retorno de 5, 50 e 100 anos, na Bacia do Rio Manuel Alves da Natividade, com destaque para o grau de dependência espacial (GD), alcance (A) e erro médio percentual absoluto obtido por validação cruzada (EMPA).
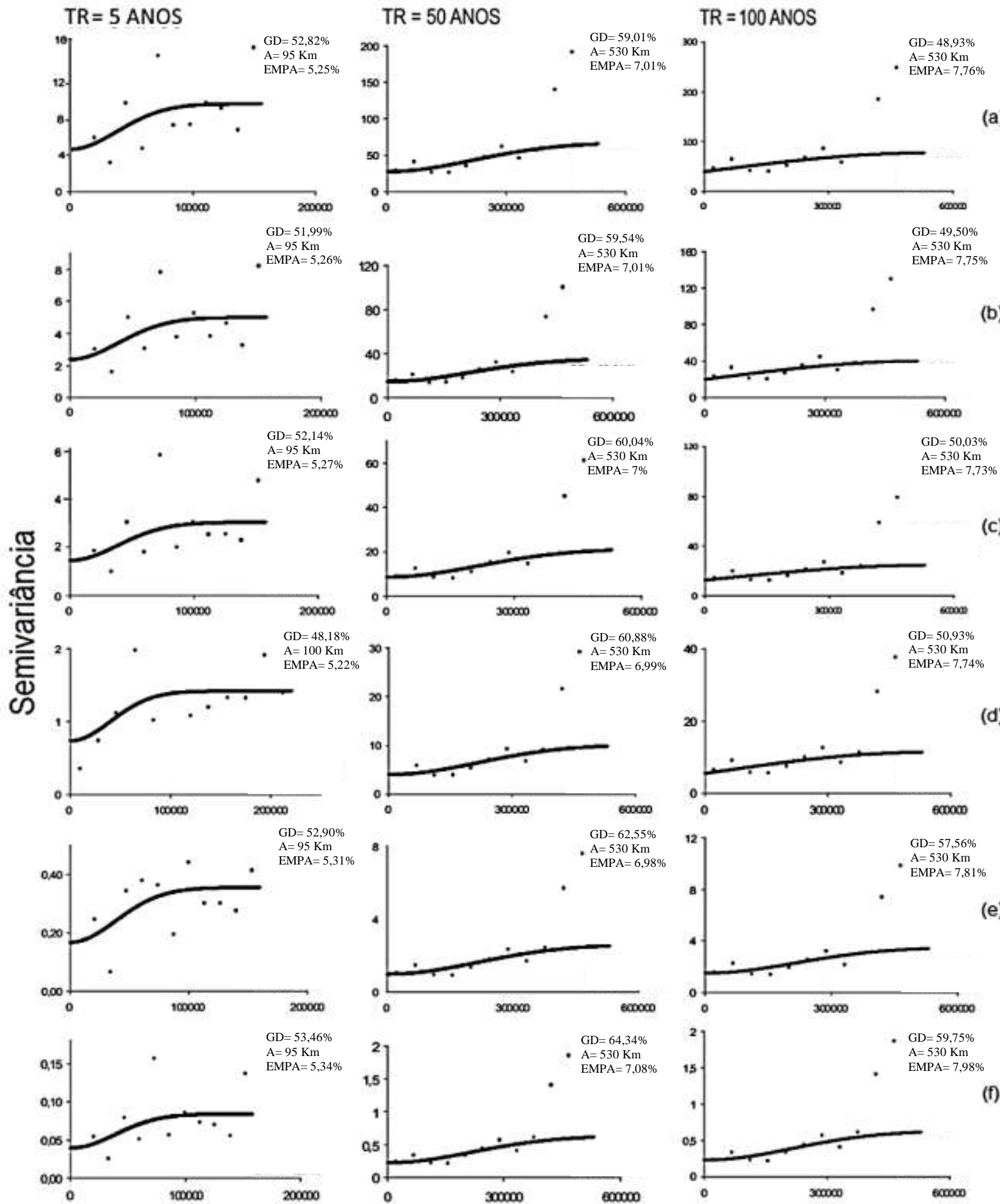

(a)
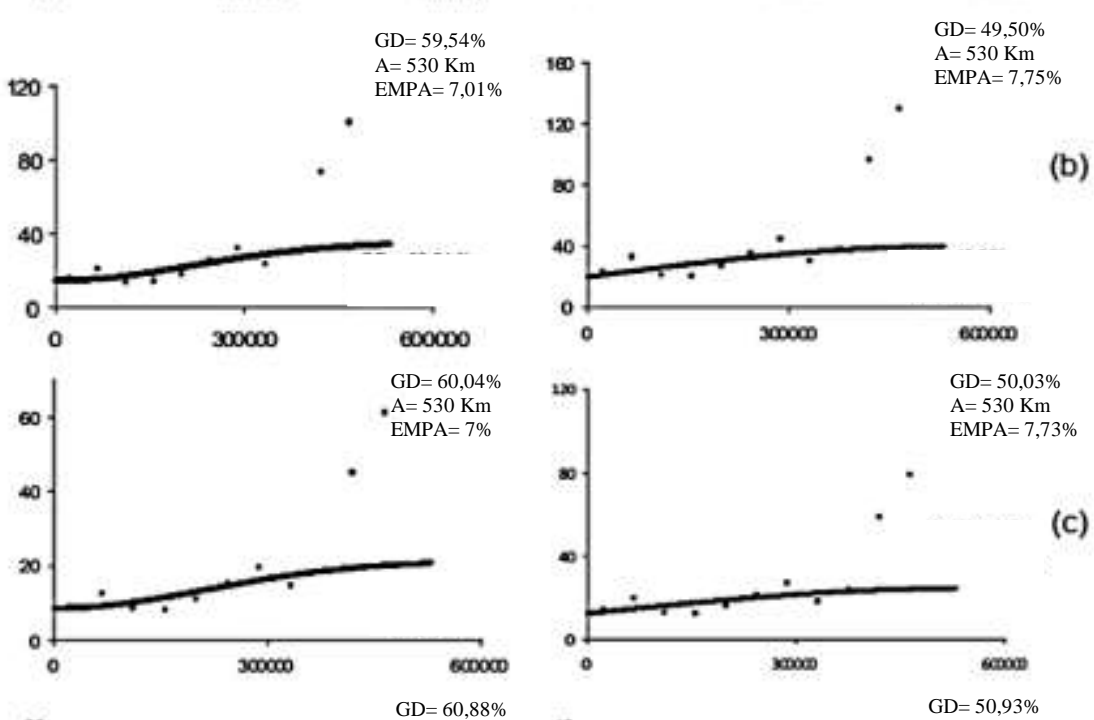

(b)
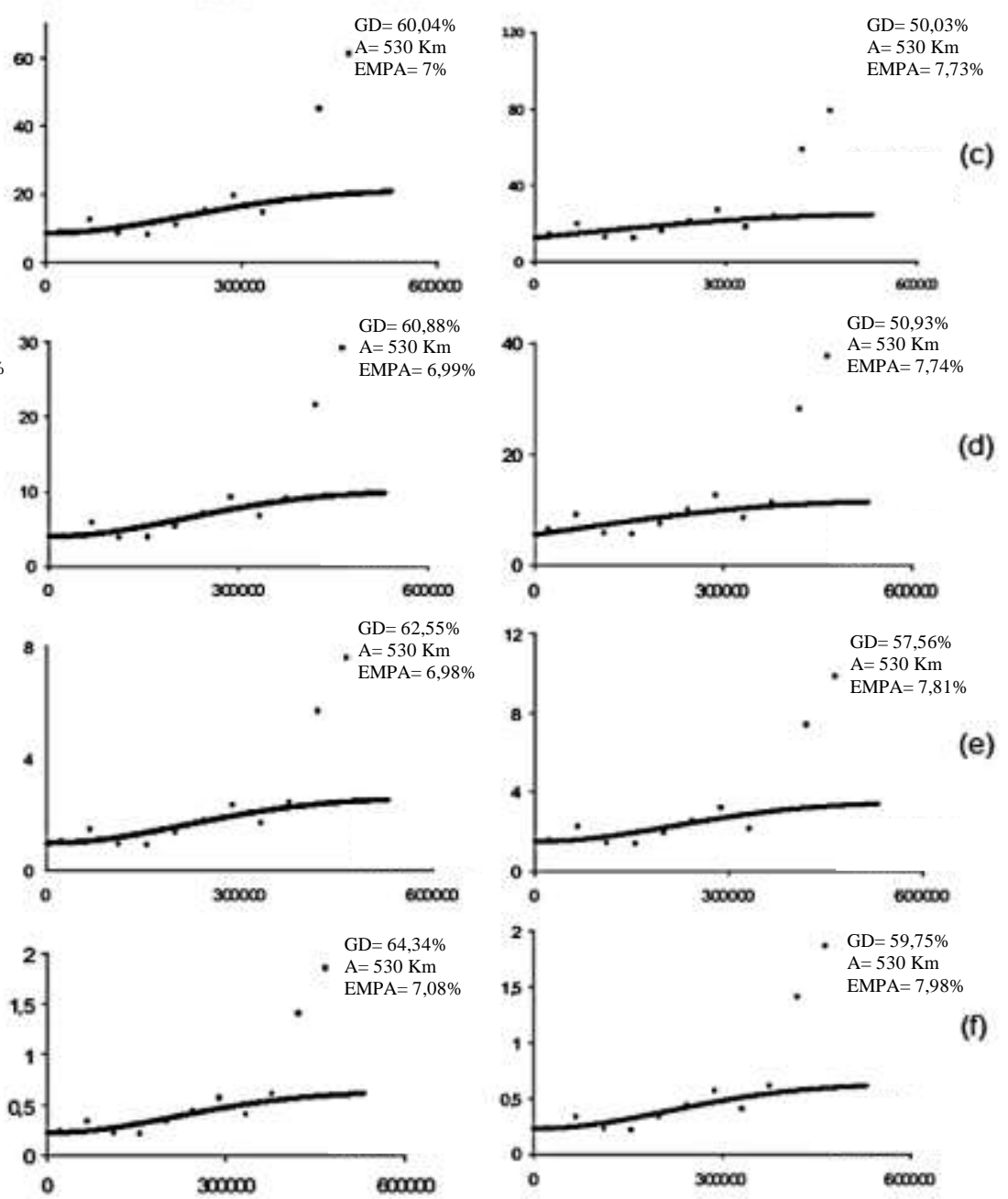

Distância (m)

Fonte: Autores. 
Nas Figuras 4 e 5, podem ser observados os semivariogramas teóricos ajustados, que demonstram o desempenho dos modelos testados por meio do grau de dependência, alcance e erro médio percentual absoluto.

Mello et al. (2012) testaram os modelos exponencial, esférico e gaussiano para estudar a continuidade espacial das grandezas precipitação pluviométrica e erosividade da chuva para o estado do Espírito Santo, Brasil, com melhor desempenho para o modelo exponencial sobre os demais modelos testados. Silva Neto (2017), no mapeamento de chuvas intensas para o Tocantins e Souza (2019), em estudos sobre regionalização climática do Tocantins, obtiveram melhores resultados no modelo esférico.

Para cada tempo de retorno foi escolhido um modelo, de acordo com o menor valor de EMPA. Desta forma, observouse que $100 \%$ dos ajustes apresentaram grau de dependência espacial moderado. A chuva intensa que apresentou maior grau de dependência espacial foi a de 1440 minutos, associada a um tempo de retorno de 50 anos. Aquele que apresentou menor GD, foi a chuva intensa de 360 minutos, associada ao tempo de retorno de 5 anos.

Observando os valores do erro médio percentual absoluto (EMPA), calculado a partir da validação cruzada, verificouse que, de maneira geral, para uma mesma duração da chuva intensa, não variaram significativamente. Observou-se que em um mesmo tempo de retorno, houve variação nos valores de EMPA, tendo alternância entre os modelos esférico e gaussiano.

O conhecimento do alcance do semivariograma é fundamental para a interpretação dos resultados obtidos pelas técnicas geoestatísticas e, em termos práticos, representa a distância limite da dependência espacial (Andriotti, 2003; Silva Neto, et al., 2020). Mello e Viola (2013) afirmaram que o alcance está associado à existência da dependência espacial e da aplicação dos princípios da autocorrelação espacial. Estes, variaram de aproximadamente 95 a $530 \mathrm{~km}$. Observou-se um aumento à medida que aumentou o tempo de retorno, porém, sem variação entre as durações de chuvas.

As Tabelas 4, 5 e 6 apresentam o grau de dependência espacial (GD), efeito pepita (C0), contribuição (C1), alcance (A), viés estatístico (BIAS) e erro médio percentual absoluto (EMPA) para os modelos de semivariograma exponencial, esférico e gaussiano, nos tempos de retorno 5, 50 e 100 anos. Apresenta-se em negrito o modelo escolhido, considerando o menor valor de EMPA.

Tabela 4 - Parâmetros dos modelos de semivariograma exponencial, esférico e gaussiano [efeito pepita (C0), contribuição (C1), alcance (A), grau de dependência espacial (GD)], tendência e erro médio percentual absoluto (EMPA), para os modelos de semivariograma exponencial, esférico e gaussiano para o tempo de retorno (TR) de 5 anos.

\begin{tabular}{|c|c|c|c|c|c|c|c|}
\hline Duração (min.) & Modelo & $\mathrm{C} 0$ & $\mathrm{~A}(\mathrm{~m})$ & $\mathrm{C} 1$ & EMPA (\%) & BIAS (\%) & GD (\%) \\
\hline & Esférico & 0,02 & 95148,82 & 0,06 & 5,43 & $-0,12$ & 72,58 \\
\hline \multirow[t]{3}{*}{1440} & Exponencial & 0,00 & 95148,82 & 0,09 & 5,37 & $-0,18$ & 100,00 \\
\hline & Gaussiano* & 0,04 & 95148,82 & 0,04 & 5,34 & $-0,09$ & 53,46 \\
\hline & Esférico & 0,10 & 95148,82 & 0,25 & 5,39 & $-0,11$ & 71,75 \\
\hline \multirow[t]{3}{*}{720} & Exponencial & 0,00 & 95148,82 & 0,36 & 5,34 & $-0,18$ & 100,00 \\
\hline & Gaussiano* & 0,17 & 95148,82 & 0,19 & 5,31 & $-0,09$ & 52,90 \\
\hline & Esférico & 0,47 & 99792,93 & 0,94 & 5,32 & $-0,05$ & 66,48 \\
\hline \multirow[t]{2}{*}{360} & Exponencial & 0,06 & 99792,93 & 1,37 & 5,27 & $-0,12$ & 95,50 \\
\hline & Gaussiano* & 0,74 & 99792,93 & 0,68 & 5,22 & $-0,05$ & 48,18 \\
\hline \multirow[t]{2}{*}{240} & Esférico & 0,87 & 95148,82 & 2,09 & 5,35 & $-0,10$ & 70,58 \\
\hline & & & 14 & & & & \\
\hline
\end{tabular}




\begin{tabular}{|c|c|c|c|c|c|c|c|}
\hline & Exponencial & 0,03 & 95148,82 & 3,02 & 5,30 & $-0,16$ & 99,12 \\
\hline & Gaussiano* & 1,44 & 95148,82 & 1,57 & 5,27 & $-0,08$ & 52,14 \\
\hline \multirow{3}{*}{180} & Esférico & 1,46 & 95148,82 & 3,46 & 5,34 & $-0,10$ & 70,34 \\
\hline & Exponencial & 0,07 & 95148,82 & 4,99 & 5,29 & $-0,16$ & 98,69 \\
\hline & Gaussiano* & 2,40 & 95148,82 & 2,60 & 5,26 & $-0,08$ & 51,99 \\
\hline \multirow{3}{*}{120} & Esférico & 2,85 & 95148,82 & 6,67 & 5,33 & $-0,09$ & 70,06 \\
\hline & Exponencial & 0,18 & 95148,82 & 9,60 & 5,28 & $-0,16$ & 98,19 \\
\hline & Gaussiano* & 4,65 & 95148,82 & 5,00 & 5,25 & $-0,08$ & 51,82 \\
\hline \multirow{3}{*}{60} & Esférico & 7,40 & 95148,82 & 17,08 & 5,33 & $-0,09$ & 69,76 \\
\hline & Exponencial & 0,58 & 95148,82 & 24,56 & 5,28 & $-0,15$ & 97,70 \\
\hline & Gaussiano* & 12,01 & 95148,82 & 12,82 & 5,25 & $-0,07$ & 51,63 \\
\hline \multirow{3}{*}{50} & Esférico & 9,11 & 95148,82 & 20,97 & 5,33 & $-0,09$ & 69,72 \\
\hline & Exponencial & 0,73 & 95148,82 & 30,15 & 5,28 & $-0,15$ & 97,63 \\
\hline & Gaussiano* & 14,76 & 95148,82 & 15,74 & 5,25 & $-0,07$ & 51,61 \\
\hline \multirow{3}{*}{40} & Esférico & 11,44 & 95148,82 & 26,30 & 5,33 & $-0,09$ & 69,69 \\
\hline & Exponencial & 0,94 & 95148,82 & 37,81 & 5,28 & $-0,15$ & 97,58 \\
\hline & Gaussiano* & 18,53 & 95148,82 & 19,74 & 5,26 & $-0,07$ & 51,58 \\
\hline \multirow{3}{*}{30} & Esférico & 14,74 & 95148,82 & 33,85 & 5,33 & $-0,09$ & 69,66 \\
\hline & Exponencial & 1,22 & 95148,82 & 48,67 & 5,28 & $-0,15$ & 97,56 \\
\hline & Gaussiano* & 23,86 & 95148,82 & 25,40 & 5,26 & $-0,07$ & 51,56 \\
\hline \multirow{3}{*}{20} & Esférico & 19,62 & 95148,82 & 45,03 & 5,34 & $-0,09$ & 69,65 \\
\hline & Exponencial & 1,62 & 95148,82 & 64,77 & 5,29 & $-0,16$ & 97,57 \\
\hline & Gaussiano* & 31,76 & 95148,82 & 33,79 & 5,26 & $-0,07$ & 51,55 \\
\hline \multirow{3}{*}{10} & Esférico & 27,22 & 95148,82 & 62,53 & 5,34 & $-0,10$ & 69,67 \\
\hline & Exponencial & 2,18 & 95148,82 & 89,98 & 5,29 & $-0,16$ & 97,64 \\
\hline & Gaussiano* & 44,08 & 95148,82 & 46,91 & 5,27 & $-0,08$ & 51,55 \\
\hline
\end{tabular}

* Interpolador com melhor desempenho. Fonte: Autores.

Na Tabela 4, observa-se que para o tempo de retorno de 5 anos, o modelo Gaussiano obteve melhor desempenho para todas as durações de chuvas que representam as situações analisadas, de 10 a 1440 minutos. 
Tabela 5 - Parâmetros dos modelos de semivariograma exponencial, esférico e gaussiano [efeito pepita (C0), contribuição (C1), alcance (A)], grau de dependência espacial (GD), tendência e erro médio percentual absoluto (EMPA), para os modelos de semivariograma exponencial, esférico e gaussiano para o tempo de retorno (TR) de 50 anos.

\begin{tabular}{|c|c|c|c|c|c|c|c|}
\hline Duração (min.) & Modelo & $\mathrm{CO}$ & $\mathrm{A}(\mathrm{m})$ & $\mathrm{C} 1$ & EMPA (\%) & BIAS (\%) & GD (\%) \\
\hline & Esférico & 0,21 & 530885,50 & 0,31 & 7,25 & 0,52 & 60,01 \\
\hline \multirow[t]{3}{*}{1440} & Exponencial & 0,17 & 530885,50 & 0,32 & 7,51 & 0,34 & 65,59 \\
\hline & Gaussiano* & 0,23 & 530885,50 & 0,41 & 7,08 & 0,83 & 64,34 \\
\hline & Esférico & 0,90 & 530885,50 & 1,23 & 7,09 & 0,50 & 57,81 \\
\hline \multirow[t]{3}{*}{720} & Exponencial & 0,77 & 530885,50 & 1,25 & 7,09 & 0,50 & 61,66 \\
\hline & Gaussiano* & 0,98 & 530885,50 & 1,64 & 6,98 & 0,80 & 62,55 \\
\hline & Esférico & 3,66 & 530885,50 & 4,69 & 7,03 & 0,49 & 56,17 \\
\hline \multirow[t]{3}{*}{360} & Exponencial & 3,30 & 530885,50 & 4,49 & 7,13 & 0,33 & 57,62 \\
\hline & Gaussiano* & 3,97 & 530885,50 & 6,18 & 6,99 & 0,78 & 60,88 \\
\hline & Esférico & 7,87 & 530885,50 & 9,78 & 7,02 & 0,49 & 55,41 \\
\hline \multirow[t]{3}{*}{240} & Exponencial & 7,24 & 530885,50 & 9,16 & 7,11 & 0,32 & 55,84 \\
\hline & Gaussiano* & 8,54 & 530885,50 & 12,83 & 7,00 & 0,77 & 60,04 \\
\hline & Esférico & 13,13 & 530885,50 & 16,03 & 7,02 & 0,49 & 54,98 \\
\hline \multirow[t]{3}{*}{180} & Exponencial & 12,16 & 530885,50 & 14,87 & 7,10 & 0,32 & 54,99 \\
\hline & Gaussiano* & 14,24 & 530885,50 & 20,95 & 7,01 & 0,77 & 59,54 \\
\hline & Esférico & 25,50 & 530885,50 & 30,57 & 7,01 & 0,49 & 54,52 \\
\hline \multirow[t]{3}{*}{120} & Exponencial & 23,78 & 530885,50 & 28,14 & 7,09 & 0,32 & 54,20 \\
\hline & Gaussiano* & 27,65 & 530885,50 & 39,82 & 7,01 & 0,76 & 59,01 \\
\hline & Esférico* & 65,81 & 530885,50 & 77,78 & 7,01 & 0,49 & 54,17 \\
\hline \multirow[t]{3}{*}{60} & Exponencial & 61,60 & 530885,50 & 71,27 & 7,09 & 0,32 & 53,64 \\
\hline & Gaussiano & 71,35 & 530885,50 & 101,06 & 7,02 & 0,60 & 58,62 \\
\hline & Esférico* & 80,85 & 530885,50 & 95,51 & 7,01 & 0,49 & 54,16 \\
\hline \multirow[t]{3}{*}{50} & Exponencial & 75,69 & 530885,50 & 87,50 & 7,09 & 0,32 & 53,62 \\
\hline & Gaussiano & 87,65 & 530885,50 & 124,09 & 7,02 & 0,76 & 58,60 \\
\hline & Esférico* & 101,42 & 530885,50 & 119,88 & 7,02 & 0,49 & 54,17 \\
\hline \multirow[t]{3}{*}{40} & Exponencial & 94,93 & 530885,50 & 109,86 & 7,09 & 0,32 & 53,64 \\
\hline & Gaussiano & 109,95 & 530885,50 & 155,81 & 7,02 & 0,76 & 58,63 \\
\hline & Esférico* & 130,51 & 530885,50 & 154,65 & 7,02 & 0,49 & 54,23 \\
\hline \multirow[t]{2}{*}{30} & Exponencial & 122,09 & 530885,50 & 141,82 & 7,09 & 0,32 & 53,74 \\
\hline & Gaussiano & 141,48 & 530885,50 & 201,15 & 7,02 & 0,76 & 58,71 \\
\hline
\end{tabular}




\begin{tabular}{cccccccc} 
& Esférico* & 173,42 & 530885,50 & 206,56 & 7,02 & 0,49 & 54,36 \\
& Exponencial & 162,00 & 530885,50 & 189,74 & 7,10 & 0,32 & 53,94 \\
& Gaussiano & 187,97 & 530885,50 & 269,03 & 7,03 & 0,76 & 58,87 \\
& & & & & & \\
$10 \quad$ & & & & & & \\
& Esférico & 240,17 & 530885,50 & 288,78 & 7,03 & 0,49 & 54,60 \\
& Exponencial & 223,74 & 530885,50 & 266,19 & 7,10 & 0,32 & 54,33 \\
& Gaussiano* & 260,28 & 530885,50 & 377,01 & 7,02 & 0,77 & 59,16 \\
\hline
\end{tabular}

* Interpolador com melhor desempenho. Fonte: Autores.

Com base na Tabela 5, para o tempo de retorno de 50 anos, o modelo Gaussiano obteve melhor desempenho para as situações analisadas para chuvas de 10,120,180, 240, 360, 720 e 1440 minutos. O modelo esférico, sobressaiu-se para todas as demais situações analisadas para este tempo de retorno.

Tabela 6 - Parâmetros dos modelos de semivariograma exponencial, esférico e gaussiano [efeito pepita (C0), contribuição (C1), alcance (A)], grau de dependência espacial (GD), tendência e erro médio percentual absoluto (EMPA), para os modelos de exponencial, esférico e gaussiano para o tempo de retorno (TR) de 100 anos.

\begin{tabular}{|c|c|c|c|c|c|c|c|}
\hline Duração (min.) & Modelo & $\mathrm{C} 0$ & $\mathrm{~A}(\mathrm{~m})$ & $\mathrm{C} 1$ & EMPA (\%) & BIAS (\%) & GD (\%) \\
\hline & Esférico & 0,32 & 530885,50 & 0,38 & 8,03 & 0,69 & $\begin{array}{l}54,62 \\
\end{array}$ \\
\hline \multirow[t]{3}{*}{1440} & Exponencial & 0,29 & 530885,50 & 0,36 & 8,19 & 0,49 & 54,75 \\
\hline & Gaussiano* & 0,34 & 530885,50 & 0,51 & 7,98 & 1,02 & 59,75 \\
\hline & Esférico & 1,38 & 530885,50 & 1,54 & 7,82 & 0,67 & 52,71 \\
\hline \multirow[t]{3}{*}{720} & Exponencial & 1,31 & 530885,50 & 1,39 & 7,96 & 0,48 & 51,62 \\
\hline & Gaussiano* & 1,49 & 530885,50 & 2,01 & 7,82 & 0,99 & 57,57 \\
\hline & Esférico* & 5,62 & 530885,50 & 5,83 & 7,74 & 0,66 & 50,93 \\
\hline \multirow[t]{3}{*}{360} & Exponencial & 5,36 & 530885,50 & 5,23 & 7,82 & 0,47 & 49,38 \\
\hline & Gaussiano & 6,04 & 530885,50 & 7,53 & 7,79 & 0,96 & 55,50 \\
\hline & Esférico* & 12,12 & 530885,50 & 12,14 & 7,73 & 0,65 & 50,03 \\
\hline \multirow[t]{3}{*}{240} & Exponencial & 11,60 & 530885,50 & 10,86 & 7,81 & 0,47 & 48,35 \\
\hline & Gaussiano & 13,02 & 530885,50 & 15,58 & 7,79 & 0,94 & 54,46 \\
\hline & Esférico* & 20,24 & 530885,50 & 19,84 & 7,75 & 0,65 & 49,50 \\
\hline \multirow[t]{3}{*}{180} & Exponencial & 19,41 & 530885,50 & 17,74 & 7,83 & 0,47 & 47,75 \\
\hline & Gaussiano & 21,74 & 530885,50 & 25,37 & 7,82 & 0,94 & 53,85 \\
\hline & Esférico* & 39,39 & 530885,50 & 37,73 & 7,76 & 0,65 & 48,93 \\
\hline \multirow[t]{2}{*}{120} & Exponencial & 37,81 & 530885,50 & 33,69 & 7,84 & 0,47 & 47,12 \\
\hline & Gaussiano & 42,29 & 530885,50 & 48,06 & 7,85 & 0,93 & 53,19 \\
\hline
\end{tabular}




\begin{tabular}{|c|c|c|c|c|c|c|c|}
\hline & Esférico* & 101,76 & 530885,50 & 95,79 & 7,78 & 0,64 & 48,49 \\
\hline \multirow[t]{3}{*}{60} & Exponencial & 97,80 & 530885,50 & 85,48 & 7,85 & 0,46 & 46,64 \\
\hline & Gaussiano & 109,21 & 530885,50 & 121,69 & 7,87 & 0,92 & 52,70 \\
\hline & Esférico* & 125,02 & 530885,50 & 117,62 & 7,78 & 0,64 & 48,47 \\
\hline \multirow[t]{3}{*}{50} & Exponencial & 120,15 & 530885,50 & 104,95 & 7,85 & 0,47 & 46,62 \\
\hline & Gaussiano & 134,16 & 530885,50 & 149,42 & 7,87 & 0,92 & 52,69 \\
\hline & Esférico* & 156,81 & 530885,50 & 147,67 & 7,78 & 0,64 & 48,50 \\
\hline \multirow[t]{3}{*}{40} & Exponencial & 150,69 & 530885,50 & 131,77 & 7,85 & 0,47 & 46,65 \\
\hline & Gaussiano & 150,69 & 530885,50 & 131,77 & 7,85 & 0,47 & 46,65 \\
\hline & Esférico* & 201,71 & 530885,50 & 190,61 & 7,78 & 0,64 & 48,59 \\
\hline \multirow[t]{3}{*}{30} & Exponencial & 193,82 & 530885,50 & 170,10 & 7,85 & 0,47 & 46,74 \\
\hline & Gaussiano & 216,46 & 530885,50 & 242,40 & 7,87 & 0,92 & 52,83 \\
\hline & Esférico* & 267,85 & 530885,50 & 254,88 & 7,77 & 0,65 & 48,76 \\
\hline \multirow[t]{3}{*}{20} & Exponencial & 257,29 & 530885,50 & 227,49 & 7,85 & 0,47 & 46,93 \\
\hline & Gaussiano & 287,45 & 530885,50 & 324,56 & 7,86 & 0,93 & 53,03 \\
\hline & Esférico* & 370,53 & 530885,50 & 357,01 & 7,76 & 0,65 & 49,07 \\
\hline \multirow[t]{2}{*}{10} & Exponencial & 355,70 & 530885,50 & 318,78 & 7,84 & 0,47 & 47,26 \\
\hline & Gaussiano & 397,70 & 530885,50 & 455,67 & 7,84 & 0,93 & 53,40 \\
\hline
\end{tabular}

* Interpolador com melhor desempenho. Fonte: Autores.

Já com base na Tabela 6, observa-se que para o tempo de retorno de 100 anos, o modelo Gaussiano obteve melhor desempenho apenas para longas durações de 720 e 1440 minutos. Para todas as demais durações, o modelo Esférico apresentou melhor desempenho.

As variações nos valores de efeito pepita significam que existe descontinuidade entre valores separados por distância menores que aquele utilizado no intervalo de amostragem. Isto é um indicativo da quantidade de variação ao acaso, de um ponto para outro, e quanto menor seus valores, mais parecidos são os valores vizinhos. O aumento do efeito pepita, alcance e erro, ocorrem com a redução do número de pontos amostrados e com o aumento da distância entre os pontos (Souza, et al., 2014). Por se tratar de valores obtidos por meio de coeficientes de desagregação de chuvas, há maior variabilidade nas amostras, tendendo a apresentar maiores alterações em chuvas de curta duração, por haver uma dependência maior dos referidos coeficientes.

O alcance (A) ou amplitude semivariográfica é à distância a partir da qual as amostras passam a ser independentes, ou seja, a partir da qual a variação média entre duas observações não é mais função da distância entre elas, dando lugar a independência, sem correlações espaciais. $\mathrm{O}$ alcance reflete o grau de homogeneização entre as amostras, ou seja, quanto maior for o seu valor, mais homogêneo será o fenômeno ou processo estudado. $\mathrm{O}$ alcance do semivariograma representa a zona de influência de uma observação e separa o campo estruturado (amostras correlacionadas) do campo aleatório (amostras independentes). Portanto, para o mesmo tempo de retorno, os valores de alcance apresentam valores semelhantes.

As Figuras 6, 7 e 8 apresentam os mapas das chuvas intensas de diferentes durações obtidas por krigagem ordinária para a bacia do Rio Manuel Alves de Natividade, associados a diferentes tempos de retorno. 
Figura 6 - Intensidade das chuvas em $\mathrm{mm} \mathrm{h}^{-1}$ para situações de 10(a), 20(b), 30(c) e 40(d) minutos, associadas aos tempos de retorno de 5, 50 e 100 anos, na Bacia do Rio Manuel Alves da Natividade.

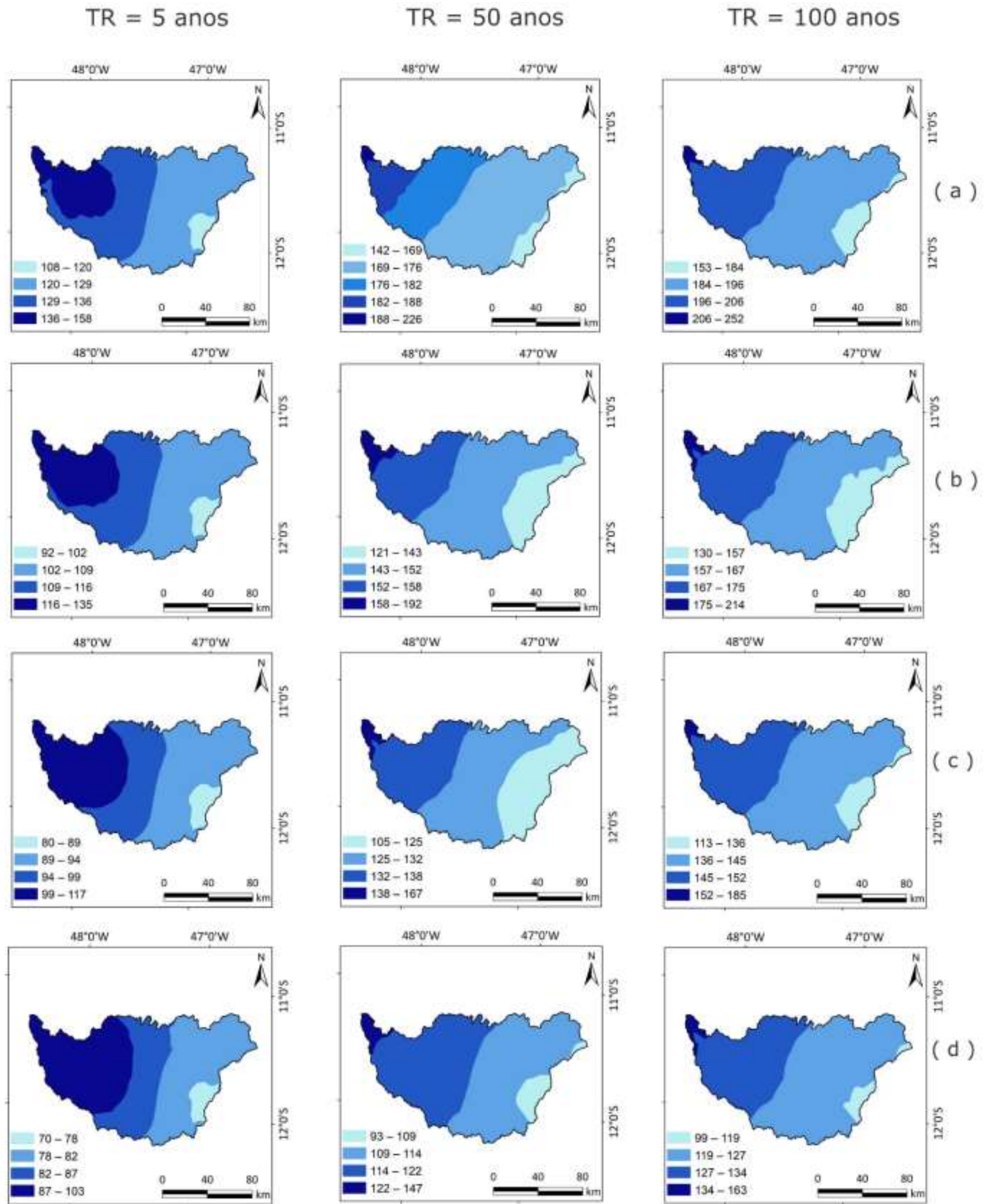

Fonte: Autores. 
Figura 7 - Intensidade das chuvas em $\mathrm{mm} \mathrm{h}^{-1}$ para situações de 50(a), 60(b), 120(c) e 180(d) minutos, associadas aos tempos de retorno de 5, 50 e 100 anos, na Bacia do Rio Manuel Alves da Natividade.

$$
\mathrm{TR}=5 \text { anos }
$$
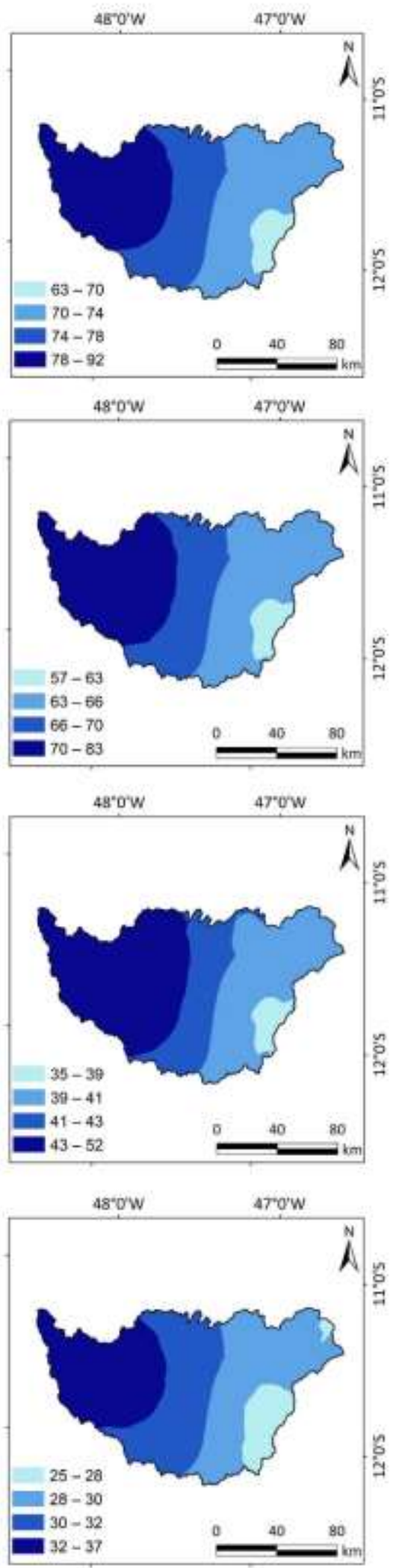

$\mathrm{TR}=50$ anos
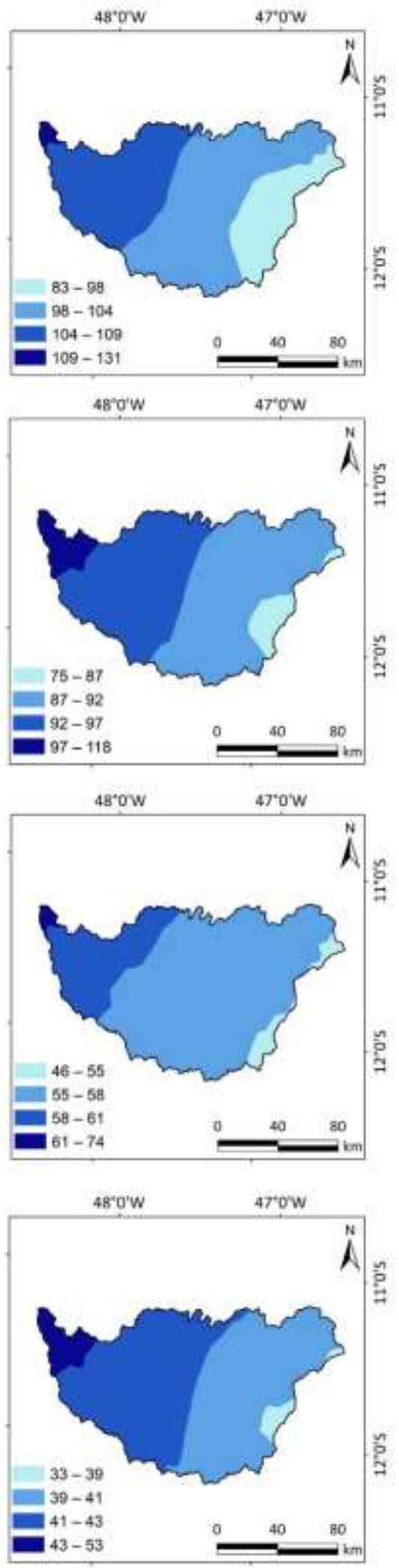

Fonte: Autores.
$\mathrm{TR}=100$ anos

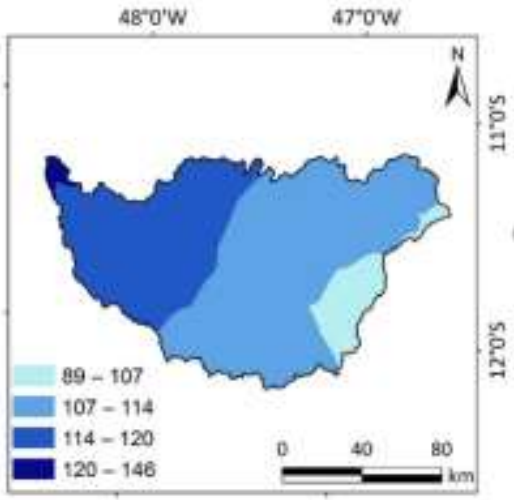

(a)

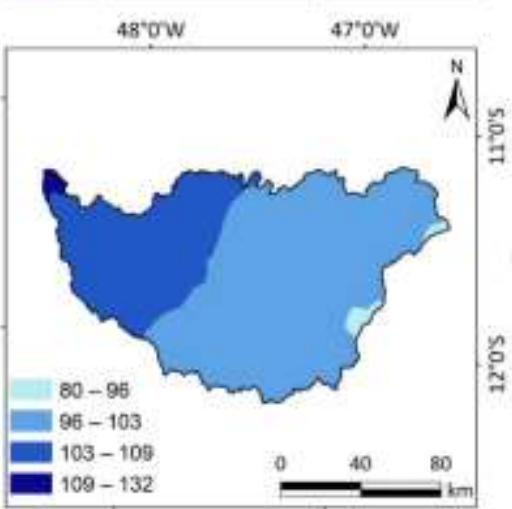

(b)

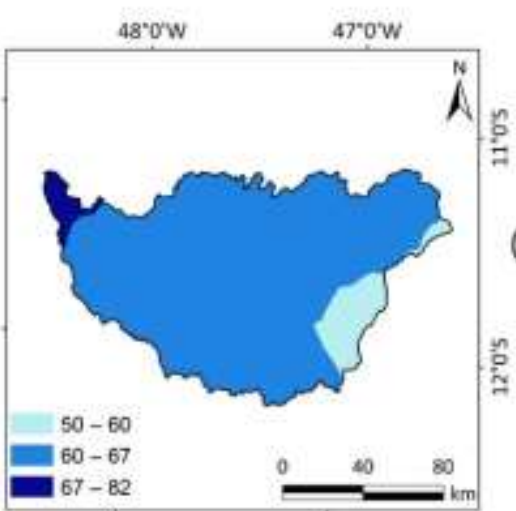

(c)

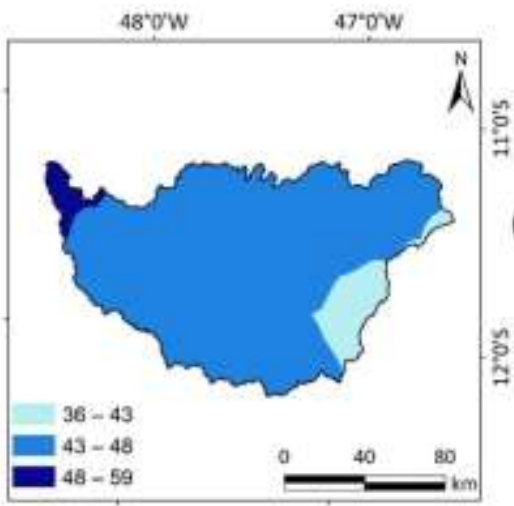


Figura 8 - Intensidade das chuvas em $\mathrm{mm} \mathrm{h}^{-1}$ para situações de 240(a), 360(b), 720(c) e 1440(d) minutos, associadas aos tempos de retorno de 5, 50 e 100 anos, na Bacia do Rio Manuel Alves da Natividade.

$\mathrm{TR}=5$ anos
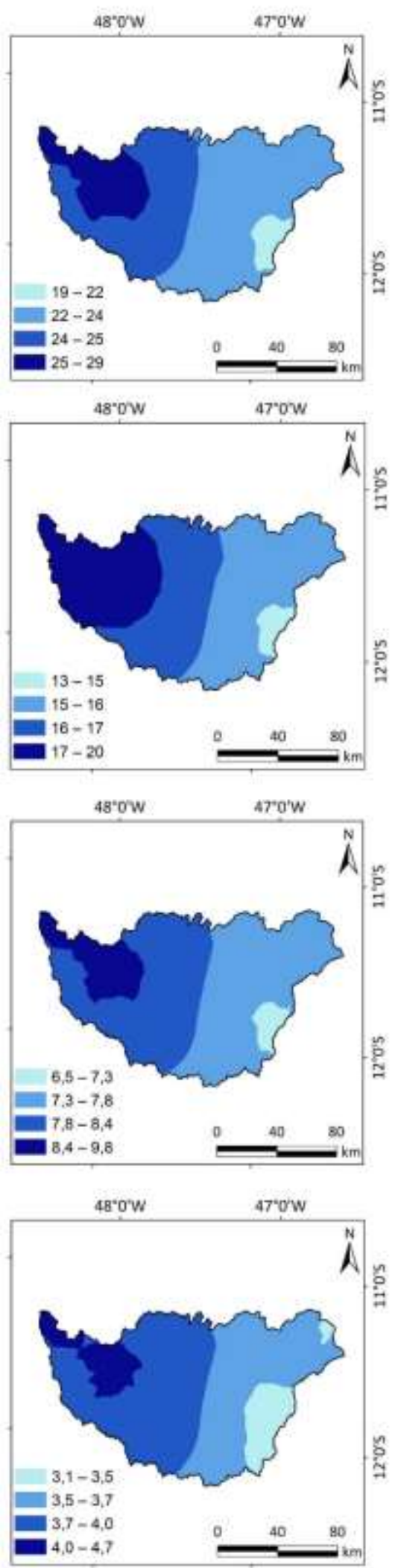

$\mathrm{TR}=50$ anos
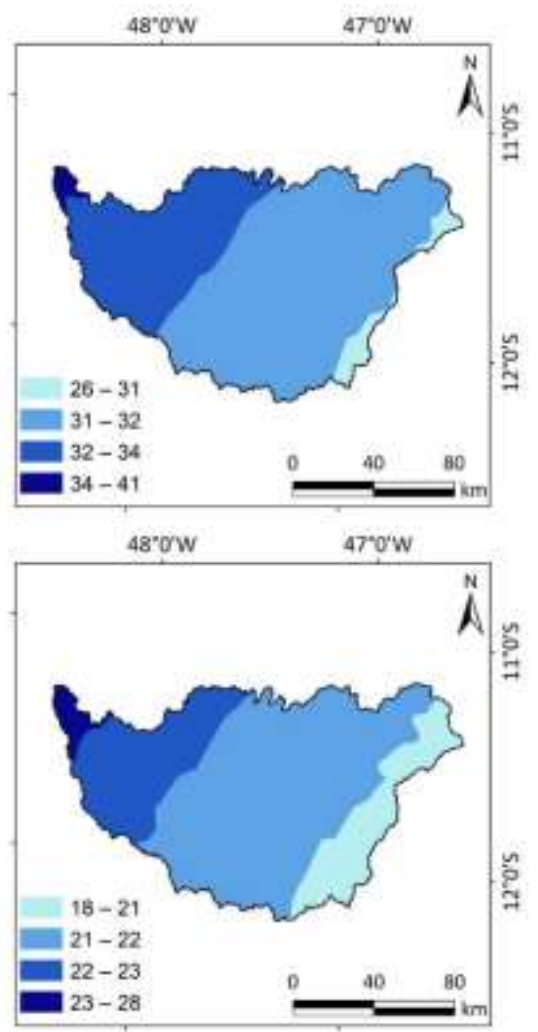

48*0'W
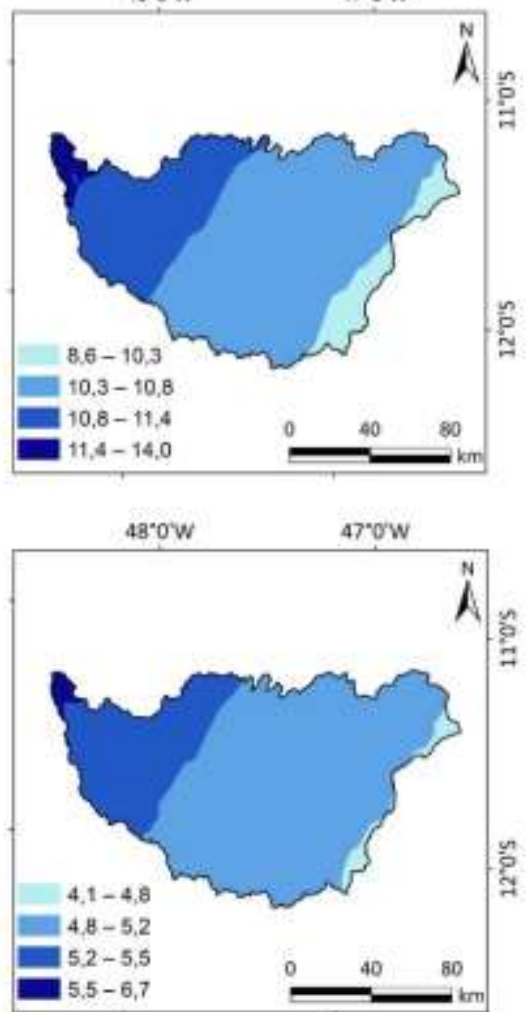

Fonte: Autores.
$\mathrm{TR}=100$ anos

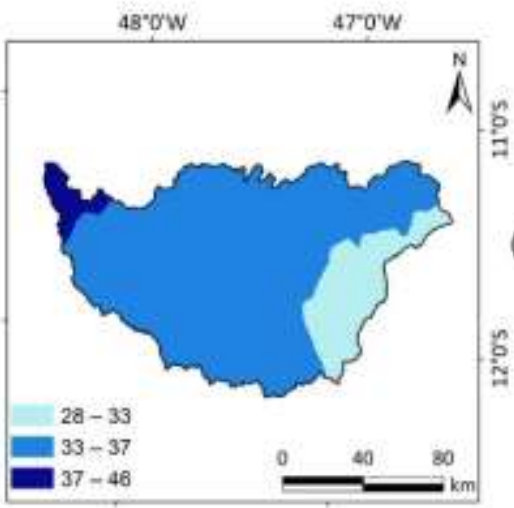

(a)

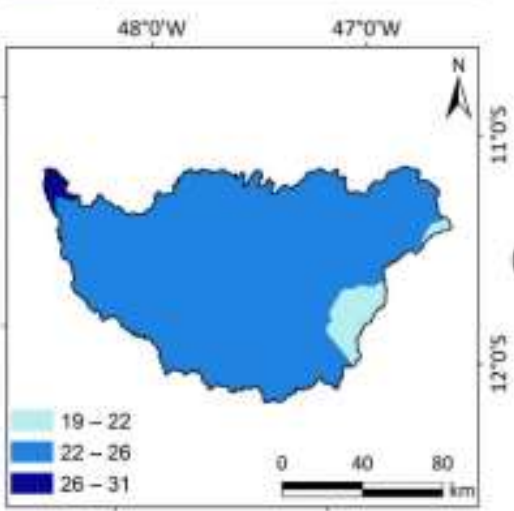

(b)

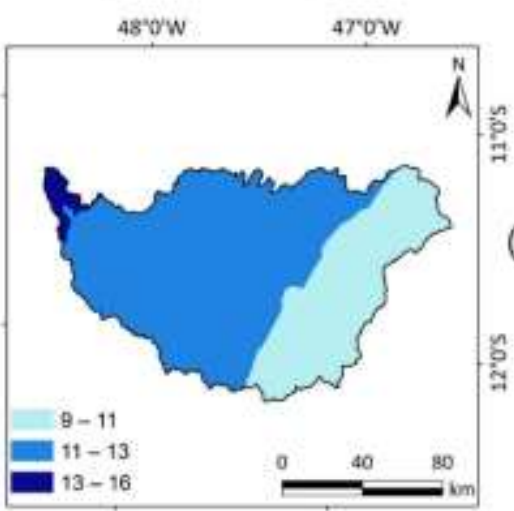

(c)

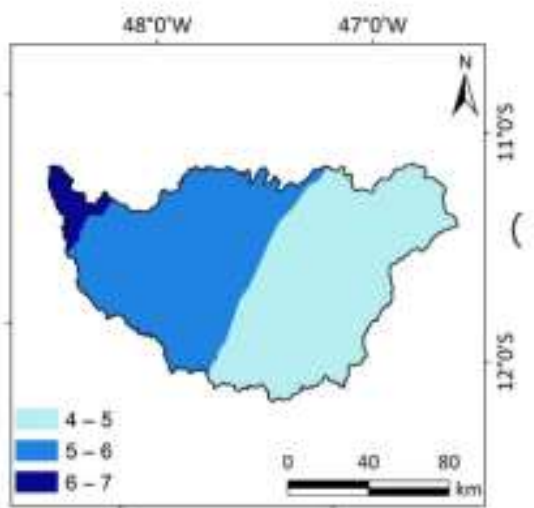


Com base nas Figuras 6, 7 e 8, pode ser constatado que as chuvas intensas estão concentradas predominantemente na porção oeste da bacia, independentemente da duração ou do tempo de retorno, apresentando gradativa redução da intensidade conforme a direção sudeste da bacia.

A análise dos mapas permite observar uma região com chuvas intensas de maior magnitude para curtas durações (10, 20, 30 e 40 minutos, considerando os 3 tempos de retorno), sendo ela na porção oeste da Bacia. Para durações de 50, 60, 120 e 140 minutos, com tempos de retorno de 5, 50 e 100 anos, a maior intensidade também se localiza na porção oeste da bacia do rio Manuel Alves da Natividade, porém, com menores valores de precipitação, dando destaque para o tempo de retorno de 100 anos. Nas durações de 240, 360, 720 e 1440, os maiores valores também foram encontrados na porção oeste da bacia, variando de 3 a $46 \mathrm{~mm} \mathrm{~h}^{-1}$.

Segundo Marcuzzo e Goularte (2013), entre o período de outubro a abril ocorre cerca de 90\% da precipitação total anual no Tocantins, prevalecendo eventos convectivos, que são caracterizados por elevada intensidade, curta duração e elevado potencial erosivo. Já para Viola et al. (2014), em termos médios para o Estado, os meses mais chuvosos são àqueles entre dezembro e março e que o Tocantins apresenta sazonalidade moderada quanto à concentração de chuvas, o que segundo Reboita et al. (2010), corresponde a uma característica marcante da região central do Brasil, em que no período seco, ocorre a intensificação do anticiclone do Atlântico Sul, com diminuição do vapor d'água na atmosfera, impedindo a formação de nuvens de chuva e o deslocamento de sistemas frontais.

A porção oeste da bacia, apesar de apresentar maiores intensidades de chuvas, é uma área de menor declividade, diminuindo os riscos de erosão. Porém, deve-se tomar cuidados conforme a prática de exploração das áreas desta região no que se refere aos impactos da erosão nos recursos hídricos, o que pode acarretar o assoreamento dos cursos d'água e reservatórios. Em estudos sobre a distribuição espacial da erosividade das chuvas nesta mesma bacia hidrográfica, Silva Neto et al. (2020) afirmam que a bacia do rio Manuel Alves da Natividade apresenta severo risco natural à erosão hídrica, principalmente nas regiões noroeste, norte e central.

Quanto aos danos socioeconômicos, destaca-se a ocorrência de inundações em rios urbanos, afetando a população que habita nas suas margens ou também a escassez de água para uma determinada população.

\section{Conclusão}

O modelo de semivariograma exponencial apresentou o melhor ajuste para o mapeamento da precipitação máxima diária anual, enquanto para todas as durações de precipitação com tempo de retorno 5, 50 e 100 anos analisadas, os valores apresentaram melhores resultados para os modelos gaussiano e esférico.

$\mathrm{Na}$ área estudada, a porção sudeste da bacia apresentou os menores valores de chuvas intensas, enquanto que a porção oeste responde pela ocorrência crítica dos eventos extremos de precipitação na bacia do rio Manuel Alves da Natividade. Portanto, é a área que necessita de maiores cuidados com relação ao uso do solo.

A produção de mapas de intensidades de chuvas, sobretudo de 30 minutos, relacionados a estudos prévios sobre a erosividade da chuva na área de estudo permite concluir que o desenvolvimento de pesquisas sobre a erosão hídrica como sendo imprescindível para o planejamento agropecuário regional.

Para contribuições futuras, sugere-se que além das chuvas intensas, novos estudos possam contemplar a abordagem no que se refere à determinação da precipitação máxima provável e precipitação mínima provável, permitindo melhor manejo dos recursos naturais como o solo e a água e otimizando sistemas de irrigação na área da bacia do rio Manuel Alves da Natividade.

\section{Agradecimentos}

Ao Instituto Federal de Educação, Ciência e Tecnologia do Tocantins pela concessão de bolsa ao primeiro autor, por 
meio dos Editais n. ${ }^{\circ}$ 11/2017/REI/IFTO, de 27 de junho de 2017 e 32/2017/REI/IFTO, de 27 de junho de 2017.

\section{Referências}

Alves, K. C. C. D. L. F., Viola, M. R., Mello, C. R. D., Giongo, M., \& Santos, A. F. D. (2016). Distribuição da precipitação mensal, anual e máxima diária anual na bacia hidrográfica do rio Formoso, Tocantins. Ambiência. 12(1), 49-70. 10.5935/ambiencia.2016.01.03

ANA - Agência Nacional das Águas. (2017). Hidroweb. Sistema de informações hidrológicas. Recuperado de http://www.snirh.gov.br/hidroweb/apresentacao

Andriotti, J. L. S. (2003). Fundamentos de estatística e geoestatística: São Leopoldo: Unisinos.

Back, Á. J., Oliveira, J. L. R., \& Henn, A. (2012). Relações entre precipitações intensas de diferentes durações para desagregação da chuva diária em Santa Catarina. Revista Brasileira de Engenharia Agrícola e Ambiental. 16(4): 391-398. org/10.1590/S1415-43662012000400009

Beskow, S., Mello, C. R. D., Coelho, G., Silva, A. M. D., \& Viola, M. R. (2009). Estimativa do escoamento superficial em uma bacia hidrográfica com base em modelagem dinâmica e distribuída. Revista Brasileira de Ciência do Solo. 33: 169-178. org/10.1590/S0100-06832009000100018

Caldeira, T. L., Beskow, S., Mello, C. R. D., Vargas, M. M., Guedes, H. A. S., \& Coll, L. F. (2016). Desagregação de chuva diária: uma análise para o Estado do Rio Grande do Sul. Revista Scientia Agraria. 16(3): 1-21. dx.doi.org/10.5380/rsa.v16i3.46320

Cambardella, C. A., Moorman, T. B., Novak, J. M., Parkin, T. B., Karlen, D. L., Turco, R. F., \& Konopka, A. E. (1994). Field-scale variability of soil properties in central Iowa soils. Soil Science Society of America Journal, Madison, 58(5), 1501-1511. doi.org/10.2136/sssaj1994.03615995005800050033x

Cardoso, C. O., Ullmann, M. N., \& Bertol, I. (1998). Análise de chuvas intensas a partir da desagregação das chuvas diárias de Lages e de Campos Novos (SC). Revista Brasileira de Ciência do Solo. 22: 131-140. dx.doi.org/10.1590/S0100-06831998000100018

Carvalho, J. R. P., \& Assad, E. D. (2005). Análise espacial da precipitação pluviométrica no Estado de São Paulo: comparação de métodos de interpolação. Engenharia Agrícola. 25(2): 377-384, maio/ago. doi.org/10.1590/S0100-69162005000200011

Carvalho, J. R. P. D., Da Silveira, P. M., \& Vieira, S. R. (2002). Geoestatística na determinação da variabilidade espacial de características químicas do solo sob diferentes preparos. Pesquisa Agropecuária Brasileira. 37(8): 1151-1159. 10.1590/S0100-204X2002000800013

CETESB. (1980). Drenagem Urbana: manual de projetos. DAEE/CETESB.

Damé, R., Pedrotti, C., Cardoso, M., Silveira, C., Duarte, L., \& Moreira, A. (2006). Comparação entre curvas intensidade-duração-frequência de ocorrência de precipitação obtidas a partir de dados pluviográficos com aquelas estimadas por técnicas de desagregação de chuva diária. Revista Brasileira de Agrociência. 12(4): 505-509. Recuperado de http://www2.ufpel.edu.br/faem/agrociencia/

Damé, R. D. C., Teixeira, C. F., Terra, V. S., \& Rosskoff, J. L. (2010). Hidrograma de projeto em função da metodologia utilizada na obtenção da precipitação. Revista Brasileira de Engenharia Agrícola e Ambiental. 14(1): 46-54. 10.1590/S1415-43662010000100007

Hernandez, V. (2008). Regionalização dos parâmetros de escala em chuvas intensas. Revista Brasileira de Recursos Hídricos. 13(1): 91-98. 10.21168/rbrh.v13n1.p91-98

IBGE - Instituto Brasileiro de Geografia e Estatística (2019). Produção agrícola municipal 2019. Recuperado Outubro 7, 2020, de https://www.ibge.gov.br/estatisticas/economicas/agricultura-e-pecuaria.

Isaaks, E. H., \& Srivastava, R. M. (1989). An introduction to applied geostatistics: Oxford University Press.

Junqueira Júnior, J. A., Silva, A. D., Mello, C. D., \& Pinto, D. B. F. (2008). Continuidade espacial de atributos Físico-Hídricos do solo em sub-bacia hidrográfica de cabeceira. Ciência e Agrotecnologia, Lavras. 32(3): 914-922. doi.org/10.1590/S1413-70542008000300032

Machado, R. L., Ceddia, M. B., Carvalho, D. F. D., Cruz, E. S. D., \& Francelino, M. R. (2010). Spatial variability of maximum annual daily rain under different return periods at the Rio de Janeiro state, Brazil. Bragantia. 69: 77-84. doi.org/10.1590/S0006-87052010000500009

Marcuzzo, F. F. N., \& Goularte, E. R. P. (2013). Caracterização do Ano Hidrológico e Mapeamento Espacial das Chuvas nos Períodos Úmido e Seco do Estado do Tocantins. Revista Brasileira de Geografia Física. 6(01): 91-99. Recuperado de http://rigeo.cprm.gov.br/jspui/handle/doc/14837

Mello, C., Ferreira, D., Silva, A.; \& Lima, J. (2001). Análise de modelos matemáticos aplicados ao estudo de chuvas intensas. Revista Brasileira de Ciência do Solo, Viçosa. 25(3): 693-698. doi.org/10.1590/S0100-06832001000300018

Mello, C. R., Viola, M. R., Curi, N., \& Silva, A. D. (2012). Distribuição espacial da precipitação e da erosividade da chuva mensal e anual no estado do Espírito Santo. Revista Brasileira de Ciência do Solo, Viçosa. 36(6): 1878-1891. doi.org/10.1590/S0100-06832012000600022

Mello, C. R. D., \& Viola, M. R. (2013). Mapeamento de chuvas intensas no estado de Minas Gerais. Revista Brasileira de Ciência do Solo. 37, 37-44. doi.org/10.1590/S0100-06832013000100004

Mello, J. M. D., Batista, J. L. F., Júnior, P. J. R., \& Oliveira, M. S. D. (2005). Ajuste e seleção de modelos espaciais de semivariograma visando à estimativa volumétrica de Eucalyptus grandis. Scientia Forestalis. 1(69): 25-37. Recuperado de https://www.ipef.br/publicacoes/scientia/nr69.aspx

Pereira A. S., Shitsuka, D. M., Parreira, F. J., \& Shitsuka, R. (2018). Metodologia da pesquisa científica. UFSM. https://repositorio.ufsm.br/bitstream/handle /1/15824/Lic_Computacao_Metodologia-Pesquisa-Cientifica.pdf?sequence=1.

Reboita, M. S., Gan, M. A., Rocha, R. P. D., \& Ambrizzi, T. (2010). Regimes de precipitacao na America do sul: uma revisão bibliográfica. Revista Brasileira de Meteorologia. 25(2): 185-204. doi.org/10.1590/S0102-77862010000200004. 
Research, Society and Development, v. 10, n. 2, e34210212673, 2021

(CC BY 4.0) | ISSN 2525-3409 | DOI: http://dx.doi.org/10.33448/rsd-v10i2.12673

Reis, M. H. D., Griebeler, N. P., Sarmento, P. H. L., Oliveira, L. F. C., \& Oliveira, J. M. (2005, Abril 16-21). Espacialização de dados de precipitação e avaliação de interpoladores para projetos de drenagem agrícola no estado de Goiás e Distrito Federal. [Publicação do trabalho nos anais do evento]. XII Simpósio brasileiro de sensoreamento remoto, Goiânia, GO, Brasil. http://marte.sid.inpe.br/col/ltid.inpe.br/sbsr/2004/11.20.04.36/doc/229.pdf

Rodrigues, J. A. M., De Oliveira Andrade, A. C., Viola, M. R., \& Morais, M. A. V. (2015). Indicadores hidrológicos para a gestão de recursos hídricos na bacia hidrográfica do rio Manuel Alves da Natividade, Tocantins. Scientia Agraria. 16(4): 58-79. dx.doi.org/10.5380/rsa.v16i4.47923

Santos, G. G., Figueiredo, C. C. D., Oliveira, L. F. C. D., \& Griebeler, N. P. (2009). Intensidade-duração-frequência de chuvas para o Estado de Mato Grosso do Sul. Revista Brasileira de Engenharia Agrícola e Ambiental. 13(Suplemento): 899-905. dx.doi.org/10.1590/S1415-43662009000700012

Silva, D. D., Gomes Filho, R. R., Pruski, F. F., Pereira, S. B., \& Novaes, L. F. (2002). Chuvas intensas no Estado da Bahia. Revista Brasileira de Engenharia Agrícola e Ambiental. 6(2): 362-367. dx.doi.org/10.1590/S1415-43662002000200030

Silva Neto, V. L., Batista, E. D., Leal Junior, W. B., Fabris, Z. V., \& Rodrigues, P. J. A. W. (2020). Distribuição espacial da erosividade das chuvas na bacia do rio Manuel Alves da Natividade, Tocantins. Sociedade \& Natureza. 32: 161-175. doi.org/10.14393/SN-v32-2020-46182

Silva Neto, V. L., Cardoso, J. A. F., Silveira Júnior, O., Batista, E. D., Araújo, A. M. M., \& Lima, I. C. S. (2021). Evaluation of spatial interpolators for improving the mapping of soil chemical attributes in banana cultivation in the Tocantins State, Brazil. Research, Society and Development. 10(1): 1-12. doi.org/10.33448/rsd-v10i1.11678

Silva Neto, V. L., Viola, M. R., Mello, C. R., Alves, M. V. G., Silva, D. D., \& Pereira, S. B. (2020). Mapeamento de Chuvas Intensas para o Estado do Tocantins. Revista Brasileira de Meteorologia. 35(1): 1-11. doi.org/10.1590/0102-7786351017

Silva Neto, V. L., Viola, M. R., Silva, D. D., Mello, C. R., Pereira, S. B., \& Giongo, M. (2017). Daily rainfall disaggregation for Tocantins State, Brazil. Revista Ambiente \& Água. 12(4): 605-617. doi.org/10.4136/ambi-agua.2077

Souza, F. H. M. D., Viola, M. R., Avanzi, J. C., Giongo, M., \& Filho, M. V. (2019). Thornthwaite's climate regionalization for the state of Tocantins, Brazil. Floresta. 49(4): 783-792. dx.doi.org/10.5380/rf.v49i4.59188

Souza, Z. M. D., Souza, G. S. D., Marques Júnior, J., \& Pereira, G. T. (2014). Número de amostras na análise geoestatística e na krigagem de mapas de atributos do solo. Ciência Rural. 44(2): 261-268. doi.org/10.1590/S0103-84782014000200011

Tucci, C. E., \& Clarke, R. T. (1997). Impacto das mudanças da cobertura vegetal no escoamento: revisão. Revista Brasileira de Recursos Hídricos. 2(1): 135152. $10.21168 /$ rbrh.v2n1.p135-152

Viola, M. R., Avanzi, J. C., Mello, C. R. D., Lima, S. D. O., \& Alves, M. V. G. (2014). Distribuição e potencial erosivo das chuvas no Estado do Tocantins. Pesquisa Agropecuária Brasileira. 49(2): 125-135. doi.org/10.1590/S0100-204X2014000200007

Viola, M. R., Mello, C. D., Pinto, D. B., Mello, J. D., \& Ávila, L. F. (2010). Métodos de interpolação espacial para o mapeamento da precipitação pluvial. Revista Brasileira de Engenharia Agrícola e Ambiental. 14(9): 970-978. doi.org/10.1590/S1415-43662010000900009 